INTERVIEW

Interview mit Anvar Nassirov,

Direktor des Internationalen Institutes für Zentralasien in Taschkent Interview mit Eldor Tulyakov,

Direktor des Zentrums für Entwicklungsstrategien in Taschkent

STATISTIK

Die Verbreitung von Covid-19 in Zentralasien (Stand: 01. August 2021)

CHRONIK

24. Mai -08. Juli 2021

(einschließlich Covid-19-Chronik)

Kasachstan

Kirgistan

Tadschikistan

Turkmenistan

Usbekistan
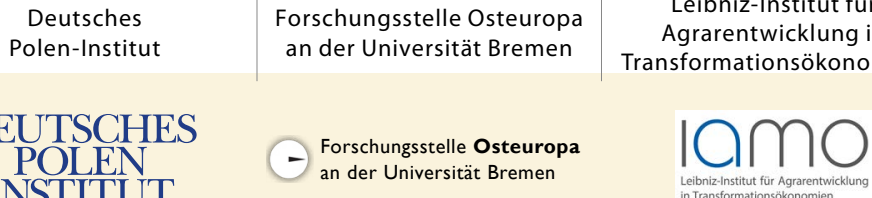

Zentrum für Osteuropa- und internationale Studien (ZOiS) gGmbH 


\title{
Zusammenarbeit in Zentralasien - Neue Tendenzen und Perspektiven
}

\author{
Birgit Wetzel, Hamburg und Berlin
}

DOI: $10.31205 /$ ZA.148.01

\section{Zusammenfassung}

Im Juni 2007 verabschiedete die EU einstimmig die erste Zentralasien-Strategie, im Mai 2019 die zweite Strategie mit dem Ziel, die Region in ihrer Zusammenarbeit und Entwicklung zu Demokratie und Marktwirtschaft nachhaltig zu unterstützen. Ihre Ziele wurden bis heute nur teilweise erreicht. Aber seit dem Tod des ersten Präsidenten von Usbekistan, Islom Karimow, und dem Amtsantritt seines Nachfolgers Schawkat Mirsijojew hat sich sowohl die regionale Zusammenarbeit, als auch die Zusammenarbeit mit der EU zunehmend entwickelt. Regelmäßige Treffen von Funktionsträgern auf unterschiedlichen Ebenen haben zum Abbau alter Rivalitätsmuster beigetragen und das Vertrauen untereinander gestärkt. Die Region hat sich im Inneren gefestigt und strukturiert, auch wenn ihr institutioneller Rahmen noch locker ist. Mit der Konferenz: »Central and South Asia« zeigen sich Ansätze einer gemeinsamen Außenpolitik, die durch das neu gegründete »International Institute for Central Asia« in Taschkent besser koordiniert werden soll. Zentralasien ist Heimat zahlreicher Binnenstaaten, welche auf Handelswege und eine Anbindung an Häfen und Weltmeere angewiesen sind. Die kürzeste Verbindung liefe durch Afghanistan, dessen Entwicklung so zu einer zentralen Frage für die gesamte Region Zentralasien wird.

\section{Der »Brückenschlag« über das Kaspische Meer}

Auf den Handschlag hat man in der EU lange gewartet. Am 21. Januar 2021 trafen sich die Präsidenten von Turkmenistan und Aserbaidschan und unterzeichneten ein Absichtsabkommen für die gemeinsame Exploration, Entwicklung aus Ausbeutung von Kohlenwasserstoffen aus dem »Dostlug«-Feld im Kaspischen Meer. Die Bedeutung des Abkommens ist gewaltig, denn damit wachsen die Aussichten, dass eine Pipeline die Gasressourcen in Zentralasien mit den im Kaukasus schon vorhandenen Leitungen verbinden wird, die bis nach Süd-Italien reichen. Die Pipeline durch das Kaspische Meer müsste nur etwa $300 \mathrm{~km}$ lang sein, und sie würde dann Zentralasien direkt mit der EU verbinden. Somit könnten begehrte Petrodollars nach Zentralasien kommen, die dort dringend gebraucht werden. Der EU würde die neue Leitung eine weitere Diversifizierung ihrer Lieferquellen über den südlichen Energie-Korridor ermöglichen.

Als Brüssel im Juni 2007 die Zentralasien-Strategie verabschiedet hatte, die u. a. eine vertiefte Zusammenarbeit der Staaten in Zentralasien zum Ziel erklärte, hoffte man auf baldige Gaslieferungen aus der ressourcenreichen Region. Doch die Hürden der Zusammenarbeit waren höher als vermutet. Eine Zusammenarbeit in der Region Zentralasien kam erst auf den Weg, als der Ukraine-Russland-Konflikt die Schwäche einzelner Staaten gegenüber Russland offenbarte und so die Staaten in Zentralasien zu einer Kooperation anregte. Nach dem Tod des usbekischen Herrschers Islom Karimow trat Präsidenten Schawkat Mirsijojew 2016 die Nachfolge an. Sein erstes Ziel war die Zusammenarbeit mit den Nachbarn. Die Kooperation nahm Fahrt auf, als die Staaten sie mit der Konferenz von Samarkand am 10./11. November 2017 in die Tat umsetzten und ihr einen vertraglichen Rahmen gaben. Die Kooperation der fünf Staaten Kasachstan, Kirgistan, Tadschikistan, Turkmenistan und Usbekistan gewinnt seitdem an Umfang und Intensität und integriert bei ihren Vorhaben auch Afghanistan.

Insbesondere ist das Vertrauen der Staaten zueinander deutlich gewachsen.

Eine neue Gaspipeline durch das Kaspische Meer würde neue Perspektiven eröffnen und eine Verwirklichung der Hoffnung auf wirtschaftlichen Aufschwung sowie Ausbau und Vertiefung der Kontakte näher rücken lassen. Ein weiterer Hoffnungsträger ist die neue Seidenstraße, die mitten durch diese Region läuft. Sie lässt Europa und China näher zusammenrücken. Das bedeutet aber noch nicht, dass die auf der Route liegenden Länder von dem zunehmenden Handel zwischen den beiden Regionen profitieren. Während die Kaufleute auf der alten Seidenstraße entlang der gesamten Strecke Handel betrieben, stehen heute die Wirtschaftszentren am Anfang und Ende der Route im Fokus. Schnell soll es zwischen beiden Räumen gehen: Nur 12 Tage brauchen die Züge von Urumchi in China bis zum Duisburger Hafen.

\section{Handelsrouten}

Handelskontakte und Exporte sind für die Binnenstaaten in Zentralasien schwierig, weil sie keinen Zugang zu den Weltmeeren haben. Zwar liefert Turkmenistan über eine mehr als $5000 \mathrm{~km}$ lange Leitung Gas nach China. Aber das Interesse an weiteren Exporten ist groß, auch in Kasachstan und Usbekistan. Sie sind wichtig, damit sich die Region nachhaltig stabil und unabhängig entwickeln kann. 
Turkmenistans großes Interesse an Gasexporten sorgte für neue Diskussionen über ein weiteres, schon fast vergessenes Projekt: die TAPI-Pipeline. Sie könnte Gas von Turkmenistan über Afghanistan und Pakistan nach Indien bringen. Scheinbar unüberwindbar verfeindete Länder soll sie durchqueren und beliefern: Afghanistan, Pakistan und Indien. Taliban-Gruppen sprachen in Turkmenistan vor und garantierten, dass sie die Leitung bewachen würden. Wie viel Vertrauen man in diese Ankündigung haben kann, bleibt fraglich, zumal die Taliban untereinander nicht immer einig sind. Es könnte aber durchaus sein, dass dieser Vorstoß eine positive Auswirkung der neuen Politik ist, die Afghanistan in die regionalen Maßnahmen für und mit Zentralasien einbezieht. Der Handel über die Grenze von Usbekistan und Afghanistan hat sich positiv entwickelt und es wird an einer besseren Stromversorgung für den Norden Afghanistans gearbeitet.

Das TAPI-Projekt wäre für Turkmenistan ein wirksamer Schritt zur Diversifizierung seiner Energieexporte. Auch für Indien, das einen steigenden Energiebedarf verzeichnet, wäre die TAPI eine weitere Energiequelle und ein weiterer Schritt für die Sicherheit seiner Energieversorgung. Allerdings hat sich mit dem Abzug der NATO aus Afghanistan die Sicherheitslage verschlechtert, so dass es fraglich erscheint, ob die Leitung tatsächlich zur Sicherheit der Versorgung beitragen könnte. Es bleibt deshalb abzuwarten, ob die Pläne angesichts er steigenden Zahl von Anschlägen der Taliban in Afghanistan Bestand haben.

Die Leitung durch das Kaspische Meer wäre eine dritte Exportroute, die auch Usbekistan und Kasachstan neue Export-Chancen einräumen würde - ein lange gehegter Plan, der schon in den 1990er Jahren die Präsidenten beider Länder beschäftigte. Jetzt, rund 25 Jahre später, könnte er Realität werden.

\section{Kooperation - für alle zentralasiatischen Staaten ein Gewinn}

Der Zusammenbruch der Sowjetunion ließ die ehemals befreundeten Sowjetrepubliken zu Rivalen werden.

Wer hat die meisten Ressourcen, welcher Staatschef hat die größte Macht? Mit der neu gewonnenen Unabhängigkeit startete jedes Land in Zentralasien eine eigene Entwicklung. So unterschiedlich wie die Ausgangslagen, so unterschiedlich waren die Herausforderungen der ersten Jahre. Keiner der Staaten war so ausgestattet, dass er unabhängig von seinen Nachbarn eine solide Wirtschaft aufbauen konnte. Hinzu kam der Mangel an Know How, wie ein unabhängiger Staat zu errichten sei.

Turkmenistan hat gewaltige Ressourcen an Gas, Kasachstan hat gewaltige Landmengen sowie Öl und Gas, Usbekistan hat Gas und Öl-Ressourcen, und es beheimatet die Hälfte der Bevölkerung Zentralasiens.
Schwieriger war es für Kirgistan und Tadschikistan, die von alledem wenig hatten, dafür aber das Wasser, das den drei anderen fehlt.

Jedes der fünf Länder musste sehen, wie es die plötzlich auftretenden Mängel in der Versorgung und in der inneren Struktur beseitigte, um einen unabhängigen Staatsaufbau zu ermöglichen. Ressourcen fehlten in jedem Land - menschliche, materielle und technische. Doch selbst wenn es die Möglichkeit gab, durch Zusammenarbeit mit den Nachbarstaaten die Mängel zu beseitigen, dann schien es ein Gebot der Zeit, eigene Wege zu gehen.

Die in der Sowjetzeit so angelegte Abhängigkeit der Staaten voneinander hatte gezeigt, wie schwierig es war, den Bedürfnissen der eigenen Bevölkerung gerecht zu werden und die Lebensverhältnisse zu verbessern. So war es zu Beginn der Unabhängigkeit.

Die desolate Lage der Staaten und ihre schwierige Ausgangslage war einigen der Staatslenker, die aus der Zentrale in Moskau in ihre Heimatländer zurückgekehrt waren, schnell klar. Als sich im Kaukasus neue Dynamiken zeigten, waren sie zur Stelle. Auch dort hatten die drei unabhängig gewordenen Staaten Armenien, Aserbaidschan und Georgien erhebliche Mühe, eine Lebensgrundlage für die Menschen sicherzustellen.

Doch ihr Glück waren das Öl und Gas in der Kaspischen Region, das westliche Energiekonzerne interessierte. Kurz nach der Unabhängigkeit kamen sie nach Baku, Aserbaidschan, und prüften die Lage. Zwar waren die Onshore-Gas- und Öl-Ressourcen weitgehend erschöpft, weshalb die Sowjetunion ihr Interesse an der Region verloren und sich den Ressourcen in Sibirien zugewendet hatte. Aber unter dem Kaspischen Meer gab es große Vorräte, die US- und britische Konzerne mit ihrer Ölbohrtechnik erschließen konnten. Die Sowjetunion kannte die Technik damals noch nicht.

Bereits im November 1999 zeichneten Energiekonzerne mit Heyder Aliyev und weiteren Staatschefs der Region Verträge zum Bau von Pipelines vom Kaspischen Meer nach Europa. Schon zu diesem frühen Zeitpunkt zählen die Präsidenten von Kasachstan und Usbekistan zu den Vertragspartnern. Exporte von Öl und Gas würden Petrodollars in die Region bringen. Kasachstan und Usbekistan, beide mit Energieressourcen ausgestattet, sahen die Chance, an der Entwicklung teilzuhaben. Während der OSZE-Konferenz in Istanbul 1999 unterzeichneten sie Pläne, die eine Verbindung von Zentralasien mit der Kaukasus-Region und ihrer neu entstehenden Infrastruktur vorsah.

Doch die Pläne kamen nicht zum Zug. Über 28 Jahre blieb der Status des Kaspischen Meeres offen und ungeklärt - nämlich ob es ein Binnenmeer oder ein See ist. Russland und sein Bündnispartner Iran sorgten dafür, dass zwar viel getagt, aber nichts beschlossen wurde. Erst 
im August 2018 unterzeichneten die Anrainer gemeinsam eine Erklärung, in der sie den Status des Gewässers als "Interkontinentalgewässer" definierten und so die Voraussetzung für weitere Pipelines nach Westen schufen.

Die Staaten in Zentralasien hatten gemeinsam Druck ausgeübt, damit eine Einigung zustande kam. Sie hatten erkannt, dass sie gemeinsam stark waren. Auslöser für diese Erkenntnis war der Krieg Russlands in der Ostukraine und die Annexion der Krim. Sie hatten den fünf Staaten in Zentralasien gezeigt, dass sie als ehemalige Bruderstaaten ein eben solches Schicksal haben könnten wie die große Ukraine. Ein Umdenken setzte ein: Die gemeinsame Furcht vor dem ehemaligen, großen Bruderstaat war stärker als der Drang zu Unabhängigkeit.

Erstmals gemeinsam präsentierten sich die fünf Staaten Zentralasiens und Afghanistan auf der "UN Conference on Security and Sustainable Development" in Samarkand im November 2017. Es war die Bühne, auf der sich auch das neue Usbekistan der internationalen Arena vorstellte. Vertreter:innen der Nachbarn und vieler weiterer Staaten waren geladen und konnten erleben, wie alle fünf zentralasiatischen Staaten eine regionale Zusammenarbeit beschlossen. Die Europäische Union stand beratend zur Seite.

\section{Die Zentralasien-Strategie - späte Erfolge}

Was die EU in sechs Jahren, von 2008 bis 2014, mit der ersten Zentralasien-Strategie erwirken wollte, nahm 2017 konkrete Form an, nämlich eine vertiefte Zusammenarbeit der Länder in Zentralasien. Deutschland war damals, im Juni 2007, die treibende Kraft in der EU gewesen. Die Abstimmung der EU für die Strategie fiel damals einstimmig aus - am letzten Tag der deutschen EU-Ratspräsidentschaft am 30. Juni 2007. Ziel war es gewesen, bilaterale Gespräche, aber auch Gespräche der zentralasiatischen Staaten untereinander anzuregen. Ein regionaler Zusammenschluss der Region mit über 70 Millionen Einwohnern ist eine wirtschaftlich interessante Größe für Investitionen. Diese werden benötigt, um die Wirtschaft aufzubauen. Die ungesättigten Märkte in Zentralasien bieten zahlreiche Möglichkeiten. Aber zunächst musste die Politik den Weg ebnen und die Rahmenbedingungen schaffen, zu denen Investoren bereit wären, sich in den neuen Markt zu begeben.

Doch es war zu früh. Die Staaten in Zentralasien brauchten noch Zeit. Die Furcht vor einer erneuten Abhängigkeit voneinander war größer als der Wunsch nach mehr Sicherheit und Stabilität miteinander. Bilaterale, politische Gespräche fanden statt, auf vielen Ebenen. Nur langsam ließen sie die Erkenntnis reifen, dass ein zunächst loser Zusammenschluss der Länder für alle von Vorteil wäre. Der Durchbruch zu einer neuen Politik kam mit den Ereignissen in der Ostukraine und auf der Krim.

\section{Der gemeinsame Rahmen}

Die neue Verbindung zwischen den Staaten in Zentralasien schafft einen Rahmen für weitere, gemeinsame Schritte, die für Sicherheit und Stabilität in der Region sorgen - zwischen den beiden großen Nachbarn Russland und China. Regelmäßige Treffen von Vertreter:innen der zentralasiatischen Staaten stehen jetzt auf der Tagesordnung und zielen auf eine gemeinsame Linie in politischen und wirtschaftlichen Fragen ab. Das wiederum stärkt die Dialoge mit Deutschland und mit der Europäischen Union. Usbekistan wird dabei immer mehr zum Zentrum und Motor der Region.

Gemeinsamkeiten in der Region gibt es viele: Die Sowjetunion sorgte in 70 Jahren für eine gemeinsame Sprache. Russisch war in allen fünf Staaten eine Amtssprache, neben den nationalen Sprachen. Einen gemeinsamen Rahmen gibt auch die Religion, ganz überwiegend der sunnitische Islam. Auch die alte Geschichte, die dieser Region über Jahrhunderte eine überwiegend gemeinsame Entwicklung bescherte, hat die Staaten bis heute eng miteinander verbunden, obwohl die Lebenswelten sehr unterschiedlich waren - und dafür sogar internationale Kontakte aufbauten in Zeiten, in denen in Europa das sogenannte dunkle Mittelalter herrschte.

Die Unterschiede der Staaten sind offenkundig. Aktuell sind die Verbindungswege, die "Connectivity«, wieder eines der wichtigsten Themen. Pläne für die Zukunft der Region setzen auf neue Handelsrouten und Energieleitungen, welche Zentralasien durchqueren und die Staaten untereinander verbinden. China unterstützt die Vorhaben mit großen Krediten und treibt damit sein Projekt der neuen Seidenstraße voran. Die neuen Straßen und Eisenbahnen schaffen neue Verkehrswege, auf denen sich der Handel entwickeln kann, sowohl in der Region als auch über die Region hinaus.

Die neuen Routen sind nicht immer überall willkommen, weil sie den Interessen Chinas und nicht denen der Region insgesamt folgen.

So begrüßt Kasachstan die Kredite aus China, die dem Land helfen, seine weit auseinander liegenden Regionen und die unterschiedlichen Wirtschaftsräume zu verbinden. $\mathrm{Zu}$ den Projekten zählen u. a. die kasachisch-chinesische Freihandelszone Khorgos, der Bau der neuen Eisenbahnverbindung von Urumchi durch Kasachstan nach Westen, sowie der Bau einer Eisenbahn- und Fährverbindung von Aktau, Kasachstan, nach Baku, Aserbaidschan. Gleichzeitig verliert Kirgistan mit der neuen Bahnverbindung Geschäfte. Die neue Linie verlagert Geschäfte weg von der Route durch Kirgistan, durch Tokmok, Bischkek und Osch, die bisher von den Handelsgeschäften zwischen China und Usbekistan, Kasachstan und Russland lebt. Allein der Dordoi-Basar, der sogenannte "Chinesenmarkt», hat geschätzte 30.000 Verkaufsstände und jährlich ange- 
nommene Umsätze von bis zu 3 Milliarden US-Dollar und damit erhebliches wirtschaftliches Gewicht in dem allgemein struktur- und wirtschaftlich schwach entwickelten Staat. Die trans-kasachstanische Bahnlinie wird die Geschäfte deutlich vermindern.

Mithilfe chinesischer Gelder plant Kirgistan sein Eisenbahnnetz zwischen der chinesischen und usbekischen Grenze auszubauen. Bei diesem Projekt geht es jedoch darum, Handelspunkte außerhalb Kirgistans miteinander zu vernetzen. Kirgistans eigene Wirtschaftszentren und Handelsgeschäfte würden hiervon allerdings weniger profitieren. Das wäre erst dann gegeben, wenn die Wirtschaft in Tadschikistan oder Afghanistan auflebt, oder die durch beide Länder führende Handelsroute zu den Häfen in Pakistan neue Perspektiven für einen Welthandel mit Zentralasien eröffnet.

Unterschiedliche Schwerpunkte, die zur Konkurrenz führen, können die Kooperationen stärken, wenn sie im Sinne von einer geteilten Aufgabe gesehen werden. So kann das ausgebaute Finanzwesen in Kasachstan und das Astana International Finance Center (AIFC) als Anlaufstelle für Investitionen in der gesamten Region fungieren.

Usbekistan setzt mit umfangreichen Reformen und Investitionen im Bildungswesen neue Schwerpunkte. Dabei schafft es neue Angebote zu Studien und Weiterbildung, die für Interessierte der ganzen Region offenstehen.

Durch die Kooperation der Staaten ist ein Wirtschaftsraum mit rund 70 Millionen Menschen entstanden, in dem eine überwiegend junge Bevölkerung von unter 30 Jahren lebt - eine interessante Größe für neue Projekte der Wirtschaft. Investitionen braucht die ganze Region, damit sich die Lage auf den Arbeitsmärkten entspannt. Noch arbeiten bis zu einem Drittel oder mehr der Bevölkerung im arbeitsfähigen Alter in einem anderen Land, meist in Russland, der Türkei oder auch in der EU. Die Migranten schicken zwar lebensnotwendiges Geld zu ihren Familien nach Hause, aber mit ihrer Abwesenheit von der eigenen Familie entstehen zusätzliche soziale Probleme im eigenen Land. Die Folgen der verfehlten Wirtschaftspolitik haben umfangreiche Auswirkungen.

Neue Programme der EU zielen darauf ab, für die Jugend (16 - 29 Jahre) mehr Bildungsangebote und neue Arbeitsplätze zu schaffen. Die Hoffnungen der EU sind, dass damit nicht nur ihr Einkommen, aber auch ihr Interesse an Partizipation im eigenen Staat steigt und so auch den Weg zu Demokratie und Marktwirtschaft stärkt.

Die ungleichen Partner in Zentralasien werden einander um so effektiver stärken, je besser sie den passenden Rahmen für ihre Zusammenarbeit finden. Zwar gilt die EU als Vorbild für eine erfolgreiche Kooperation, doch es scheint sinnvoll, Anpassungen an die
Region und die sich noch entwickelnde Zusammenarbeit vorzunehmen. Die EU hat eine Erfolgsgeschichte, doch mittlerweile gibt es auch deutlich sichtbare Schwächen. Wie können trotz großer Unterschiede gemeinsame Lösungen gefunden werden? Zentralasien kann von den Erfahrungen der EU profitieren und für die Region einen Rahmen der Zusammenarbeit schaffen, der ihren Zielen entspricht.

Durch die Zusammenarbeit gibt es bereits einige Erfolge - auch wenn sich nicht alle Staaten mit gleicher Intensität daran beteiligen: Regelmäßige Treffen der Akteure auf mehreren Ebenen, einen vertraglich gesicherten Status des Kaspischen Meeres, die erfolgreiche Bilanz im Wassermanagement, eine sich stetig entwickelnde Kooperation im Ausbau der Energieerzeugung und Energieleitung - und deutlich steigende Besucherzahlen und Handelsgeschäfte - über die nationalen Grenzen hinweg. Alle fünf Staaten arbeiten am Abbau der Bürokratie und am Aufbau von sozialen Programmen, Verbesserungen im Gesundheitswesen und zukunftsorientierten Schulen. Gemeinsam werden sie den Tourismus fördern. Sie haben schon ein Etappenziel erreicht, indem sie das "Silkroad Visum» als gemeinsames Reisedokument für Kasachstan, Usbekistan und Kirgistan planen. Auch der Kampf gegen Korruption, Drogenhandel, extremistischen Terror und Menschenhandel läuft über die Landesgrenzen hinweg und kann nur gemeinsam erfolgreich geführt werden. Der Austausch von Informationen, Erfahrungen und erfolgreichen Konzepten wird von den nationalen Organisationen dankbar angenommen.

Die Staaten in Zentralasien sind ungleiche Partner. Sie stehen noch am Anfang der Kooperation. Jedes Land entwickelt seine Schwerpunkte, die es in den gemeinsamen Rahmen einbringt. Jedes der autoritären Regime muss zugunsten der eigenen Ziele ein Stück Souveränität abgeben. Es wird viel diplomatisches Geschick und Geduld nötig sein, um Spannungen auszugleichen und zu einem gemeinsamen Handeln in der Region und gegenüber den großen Nachbarn zu kommen.

Aber den Akteuren in Zentralasien ist klar, dass sie durch gemeinsames Handeln ihre Zukunft besser und mit eigenen Zielen gestalten können. Heute lässt vor allem die Politik Usbekistans und Kasachstans erwarten, dass zwischenstaatliche Probleme gelöst werden und Zentralasien als Region stärker zusammenwächst. Für die gemeinsame Arbeit in der Region wurde im vergangenen Herbst in Taschkent ein neues "Internationales Institut für Zentralasien« eröffnet.

Es wird eine wichtige Aufgabe sein, die Anforderungen in der Region entsprechend den Potenzialen der Länder zu verteilen und dafür einen passenden Rahmen zu finden, der die Region und ihre großen Potenziale erschließt. Ob es dabei auch zu einer fruchtbaren 
Zusammenarbeit mit Afghanistan kommen wird, ist nach dem jüngsten Wiedererstarken der Taliban eine noch offene Frage. In Taschkent besteht der klare Wille, ein gutes Einvernehmen zu erreichen.

Durch die gerade verkündete Zusammenarbeit zwischen den Regionen Zentralasien und Südasien stehen weitere Handelsverbindungen in Aussicht. Handelsrouten zu den Häfen in Pakistan, und von dort über die Weltmeere würden die Staaten in Zentralasien aus der geografischen Isolation führen und sie an den Welthandel anschließen.

Über die Autorin:

Birgit Wetzel ist Expertin für Energie, Zentralasien, Kaukasus und Osteuropa. Sie arbeitet als freie Journalistin in Berlin und Hamburg (www.birgitwetzel.de).

INTERVIEW

Dr. Birgit Wetzel, Autorin des Leitartikels dieser Ausgabe, war Mitte Juli anlässlich der Konferenz »Central and South Asia: Regional Connectivity. Challenges and Opportunities« in Taschkent. Dort hatte sie Gelegenheit, zwei Interviews zu führen:

Frau Dr. Wetzel sprach dort zum einen mit Eldor Tulyakov, Direktor des Zentrums für Entwicklungsstrategien in Taschkent. Das Institut dient als Koordinationsstelle für die usbekischen Reformprozesse, welche seit dem Amtsantritt von Präsident Schawkat Mirisjojew anhalten. Das Gespräch gibt einen Einblick in die strukturelle Umsetzung der Reformen in Usbekistan. Vorweg sei angemerkt, dass es sich hierbei um eine staatliche Perspektive auf die Prozesse handelt. Um diese Perspektive zu erweitern, bietet sich ein Blick in die Usbekistan-Chronik, aber auch auf unabhängige Beobachtungsstellen an.

Das zweite Gespräch führte Frau Dr. Wetzel schriftlich mit Anvar Nassirov, Direktor des neugegründeten »International Institut for Central Asia«.

Die Redaktion der Zentralasien-Analysen

\section{Interview mit Anvar Nassirov, Direktor des Internationalen Institutes für Zentralasien in Taschkent}

Anvar Nassirov ist Direktor des "International Institute for Central Asia». Das Institut arbeitet seit dem Herbst 2020. Am 15. Juli 2021 wurde es im Vorfeld der Konferenz "Central and South Asia: Regional Connectivity. Challenges and Opportunities« offiziell eröffnet. Es koordiniert die nach außen gerichteten Aktivitäten der regional zusammen arbeitenden Staaten Kasachstan, Kirgisistan, Tadschikistan, Turkmenistan und Usbekistan.

\section{Was sind die Aufgaben des Internationalen Instituts in Usbekistan?}

In seiner Rede vor der UN-Generalversammlung im Jahr 2017 erklärte der usbekische Präsident Schawkat M. Mirsijojew Zentralasien zur höchsten Priorität der usbekischen Außenpolitik. Er äußerte seine Bereitschaft, mit den anderen Staaten der Region in einen konstruktiven Dialog zu treten, um die nachbarschaftlichen Beziehungen zwischen den Ländern Zentralasiens zu verbessern und deren nachhaltige Entwicklung sicherzustellen.

Dank der vom usbekischen Präsidenten vorangetriebenen Politik ist es mittlerweile international anerkannt, dass sich die politische Atmosphäre in Zentralasien in den letzten Jahren massiv gewandelt hat. Das gegenseitige Vertrauen und die nachbarschaftlichen Beziehungen haben sich deutlich verbessert.

Die Länder Zentralasien sind durch ein gemeinsames historisches und kulturelles Erbe sowie eine gemeinsame Religion miteinander verbunden. In der Region besteht ein enormes Potenzial, bestehende Transportrouten zu diversifizieren, die industrielle Zusammenarbeit zu stärken, gemeinsam neue Märkte zu erschließen und ein günstiges Investitionsklima zu schaffen. 
Im August 2020 wurde per Dekret des Präsidenten der Republik Usbekistan ein staatliches Forschungszentrum geschaffen - das Internationale Institut für Zentralasien (International Institute for Central Asia, IICA). Es ist die einzige Institution dieser Art in der Region.

Die Gründung des Instituts spiegelt die Prioritäten der usbekischen Außenpolitik wider,

- $\quad$ einen offenen und konstruktiven Dialog mit unseren nächsten Nachbarn zu führen; sowie

- regionale Fragen und Probleme auf der Grundlage der Prinzipien der Gleichheit, der wechselseitigen Anerkennung von Interessen und des Strebens nach vernünftigen Kompromissen zu lösen.

Vor diesem Hintergrund sind die Hauptaufgaben des Internationalen Instituts:

Erstens, die interdisziplinäre Untersuchung kultureller Vielfalt und moderner, nachhaltiger Entwicklungsprozesse in Zentralasien.

Zweitens, umfassende Forschungen zur aktuellen Außenpolitik und den internen politischen und sozioökonomischen Entwicklungen in den Ländern der Region.

Drittens, die Entwicklung konkreter, praktischer Vorschläge und Empfehlungen, wie die Zusammenarbeit in den Bereichen Politik, Handel und Wirtschaft, Soziales, Energiewesen, Transport und Kommunikation, Wasser und Umwelt, Kultur und humanitäre Arbeit im beiderseitigen Interesse weiterentwickelt werden kann.

Viertens, die Analyse der gemeinsamen Aufgaben, vor denen die Staaten in der Region in verschiedenen Bereichen stehen. Dabei sollen sowohl der aktuelle Stand als auch die möglichen Aussichten für gemeinsame Lösungen untersucht werden. Zu den relevanten Themenfeldern gehören unter anderem Fragen der Sicherheit, der Wasserversorgung, des Grenzverlaufs, der industriellen Zusammenarbeit, des Transports und Transits, der Landwirtschaft, des Tourismus, der Wissenschaft usw.

Außerdem erforscht das Institut das historische und kulturelle Erbe Zentralasiens und untersucht, welche Erfahrungen sowohl die Länder in der Region als auch Staaten weltweit beim Erhalt und der Förderung kultureller und nationaler Werte gemacht haben.

Auch an der wissenschaftlichen Forschung zu den brennenden Umweltproblemen der Region möchte sich das Institut beteiligen, insbesondere rund um den Aralsee, der auf eine Initiative unseres Präsidenten hin von der UN zu einer Zone für ökologische Innovationen und Technologien erklärt werden soll.

$\mathrm{Zu}$ den Hauptaufgaben des Instituts gehört auch die Untersuchung der Probleme Afghanistans, womit zu einer positiven, friedlichen Entwicklung des Landes beigetragen werden soll. Afghanistans Stabilität und Sicherheit sind für die aktuellen Entwicklungen in Zentralasien von zentraler Bedeutung.

Wichtig ist, darauf hinzuweisen, dass das Internationale Institut eine unabhängige Forschungseinrichtung ist, die den Prinzipien von wissenschaftlicher Objektivität, Zuverlässigkeit und Relevanz verpflichtet ist.

Unserem Institut sind große Aufgaben anvertraut worden, um den Austausch zwischen den zentralasiatischen Staaten zu stärken und weiterzuentwickeln.

\section{Mit welchen Partnern arbeitet das Internationale Institut zusammen?}

Als staatliche Forschungseinrichtung mit einem internationalen Status ist unser Institut darauf ausgerichtet, einen engen Austausch zwischen nationalen und internationalen Wissenschaftszentren und Wissenschaftler:innen, internationalen Organisationen und dem Privatsektor zu ermöglichen.

Um die notwendige Objektivität und Unparteilichkeit zu gewährleisten, arbeitet das Internationale Institut eng mit Repräsentant:innen des öffentlichen und privaten Sektors, zivilgesellschaftlichen Akteur:innen und namhaften usbekischen Wissenschaftler:innen und Expert:innen zusammen. Dazu gehören unter anderem das Außenministerium, das Ministerium für Investitionen und Außenhandel, das Institut für Strategische und Interregionale Studien unter der Schirmherrschaft des Präsidenten der Republik Usbekistan, das Informations- und Analysezentrum für Internationale Beziehungen und das Zentrum für Ökonomische Forschung und Reformen.

Um Kontakte zu knüpfen und Kooperationen in die Wege zu leiten wurden Treffen mit Vertreter:innen der kasachischen und tadschikischen Botschaften in Usbekistan, dem Repräsentanten des UN-Regionalzentrums für Präventive Diplomatie in Zentralasien und dem Regionalbeauftragten der Konrad-Adenauer-Stiftung in Taschkent organisiert.

Wie sie wissen ist die Konrad-Adenauer-Stiftung für ihre starke Vernetzung mit führenden Think-Tanks bekannt. Vor diesem Hintergrund konnte eine Vereinbarung erzielt werden, gemeinsame Veranstaltungen, Projekte und Studien zu organisieren, die sowohl europäische Expert:innen als als auch Vertreter:innen der Länder Zentralasiens miteinbeziehen.

Während sich das Institut noch im Aufbau befindet, wollen wir vielfältige Beziehungen mit führenden Forschungseinrichtungen in und außerhalb von Zentralasien sowie den Zentralasienexpert:innen internationaler Organisationen knüpfen.

Im Augenblick ist es für das Institut von besonderer Bedeutung, führende regionale und internationale ThinkTanks im Bereich der Zentralasienforschung als Kooperationspartner:innen zu gewinnen, um mit ihnen zusammen 
neue Projekte zu entwickeln, die das Institut bekannter machen und seine Reichweite erhöhen können. Es ist für uns wichtig, dass unsere Arbeit wahrgenommen wird. Deshalb arbeiten wir daran, durch die Aktivitäten des Instituts auf breiter Ebene sichtbarer zu werden und Partnerschaften mit ausländischen Expert:innen aufzubauen.

Wir wollen eines der maßgeblichen Forschungsinstitute im Bereich der Zentralasienwissenschaften aufbauen, das sich aktiv an internationalen Forschungs- und Diskussionsforen beteiligt.

\section{Wie bewertet das Internationale Institut das Potenzial für die weitere regionale Zusammenarbeit?}

Bekanntermaßen ist Zentralasien aufgrund der wirtschaftlichen, kulturellen und humanitären Prozesse, die sich in der Region vollziehen, in den letzten Jahren vermehrt in den Fokus unterschiedlicher Fachkreise gerückt.

Immer mehr Forscher:innen, Institute, Think-Tanks und internationale Organisationen sind daran interessiert, mit Wissenschaftler:innen aus Usbekistan und anderen zentralasiatischen Ländern in Kontakt zu treten, um an gemeinsamen Forschungsprojekte zu arbeiten und Erfahrungen und Wissen auszutauschen.

Das Institut beschäftigt Fachleute, die über Erfahrung mit analytischer Arbeit in den verschiedenen, für die Region Zentralasien relevanten Feldern - Wirtschaft, Energiefragen, Ökologie, kulturelle und humanitäre Forschung - und auch mit diplomatischer Arbeit im Ausland, vor allem in anderen zentralasiatischen Ländern, verfügen.

Unser Ziel ist, eine Plattform zu schaffen, die es den Expert:innen, die mit uns zusammenarbeiten, ermöglicht, ihre Meinungen und Visionen zu aktuellen Prozessen und vielversprechenden Trends in der Region zu diskutieren.

Geplant ist die Veröffentlichung verschiedener Sammlungen von analytischen Materialien, die von Expert:innen des Internationalen Instituts und ausländischen Partner:innen erarbeitet werden. Auf unseren offiziellen Seiten in den sozialen Medien und auf unserer Internetseite werden wir täglich Nachrichten veröffentlichen und objektiv über die Länder Zentralasiens und die Entwicklungen in der Region informieren.

Gleichzeitig gehört es zu den zentralen Aufgaben des Instituts, internationale Konferenzen, Seminare, runde Tische und Meetings zu organisieren. Außerdem sollen gemeinsame Forschungsprogramme und Projekte mit ausländischen Partner:innen realisiert werden.

Deshalb soll im Juni diesen Jahres in Taschkent eine internationale Konferenz mit hochrangigen Teilnehmer:innen zum Thema "Regionale Verflechtung in Zentral- und Südasien. Herausforderungen und Chancen" stattfinden, die bereits in der Ansprache des usbekischen Präsidenten an das Parlament am 29. Dezember 2020 angekündigt wurde.

\section{Mit welchen Herausforderungen ist das Internationale Institut konfrontiert?}

Mit ihren unkontrollierten Informationsflüssen, der Verbreitung von Fehlinformationen und „Fake News«s stellt die moderne globalisierte Welt alle Wissenschaftler:innen, Forscher:innen und Think-Tanks vor neue technologische und politische Herausforderungen.

Für das Internationale Institut ist die Objektivität seiner Forschung von hoher Bedeutung. Sie soll zur Annäherung zwischen den Ländern der Region beitragen und die Entwicklung gemeinsamer Lösungsansätze ermöglichen, welche die wechselseitigen Interessen der zentralasiatischen Staaten berücksichtigen.

Basierend auf den Prinzipien der Unabhängigkeit, Offenheit und Objektivität wird das Institut versuchen, seine verschiedenen Ansätze und Visionen weiterzuentwickeln, um die Konnektivität und Entwicklung der Region zu fördern.

Gleichzeitig sollen die Forschungsergebnisse praktische Relevanz besitzen und die Interessen der Länder in der Region berücksichtigen.

Aus dem Englischen von Armin Wolking

\section{Interview mit Eldor Tulyakov, Direktor des Zentrums für Entwicklungsstrategien in Taschkent}

Unter Islom Karimow war Usbekistan jahrzehntelang abgeschottet und wurde diktatorisch regiert. Nachfolgepräsident Schawkat Mirsijojew setzt zunehmend Reformen durch, auch wenn wichtige Strukturen noch auf Veränderung warten: Parteien, welche für die bevorstehenden Präsidentschaftswablen kandidieren wollten, wurde die Registrierung verweigert, beim globalen Pressefreiheitsindex von Reportern ohne Grenzen belegt Usbekistan den 157. von 180 Plätzen. Dennoch, im 
bevölkerungsreichsten Land Zentralasiens hat sich das politische Klima verändert. Ein wichtiges Instrument zum Steuern der vielen Reformen ist das "Development Strategy Center«: Mittels statistischer Erhebungen beobachtet und fordert das Institut Reformen von Regierung und Parlament ein, gibt Neuerungen bekannt und bietet eine Plattform für Diskussionen.

\section{Was sind die Hauptthemen, mit denen Sie und Ihr Institut sich beschäftigen?}

$\mathrm{Zu}$ unseren Hauptprioritäten gehört die Überwachung der laufenden Reformen im Rahmen der Aktionsstrategie für 2017 bis 2021 sowie jährliche, staatliche Programm. Anlässlich der bevorstehenden Präsidentschaftswahlen schauen wir inwiefern die Aktionsstrategie bereits ihre Wirksamkeit entfalten konnte. Wir schauen also genau bei einzelnen Ministerien und Behörden was sie bislang im Rahmen der Aktionsstrategie erreicht haben und was nicht.

(...)

Zudem arbeiten wir daran, Informationen über die im Rahmen der Aktionsstrategie erzielten Reformen zu sammeln. Diese Informationen sind in erster Linie für unsere Staatsbürger:innen gedacht. Wir wollen aber auch die internationale Gemeinschaft über die Reformen im Land informieren. Daher haben wir uns selbst als Ziel gesetzt, so präzise wie möglich zu arbeiten, um so konkrete Daten und Zahlen zu liefern. Hierbei ist es besonders wichtig zu erwähnen, dass wir daran arbeiten diese Informationen vergleichend darzustellen.

Unsere Arbeit wird auch öffentlich angehört. In jüngster Zeit haben wir öffentliche Anhörungen zu einer Vielzahl von Themen durchgeführt. Dazu zählen Rentenfonds, Bildungsfragen, Impfungen sowie Fragen zur wirtschaftlichen Entwicklung.

\section{Erhalten Sie auch Feedback von den Menschen?}

Die Informationen, die wir veröffentlichen, sind sehr spezifisch. Dementsprechend erhalten wir Feedback aus einer anderen Gruppe von Menschen. Aufgrund der Themen, mit denen wir uns beschäftigen, kommen die Kommentare von normalen Menschen, Expert:innen, und auch Staatsangestellten - sowohl aus dem Inland als auch aus dem Ausland. Ich sollte erwähnen, dass die usbekische Gesellschaft in den sozialen Netzwerken sehr aktiv ist. Wenn wir also etwas online publizieren, bekommen wir mehr Kommentare dazu. Wir haben auch Kritiker:innen. Journalist:innen sagen uns regelmäßig, dass wir uns mit diesem oder jenem Thema beschäftigen sollen. Dafür sind wir offen. Wir bewerten die Sinnhaftigkeit solcher Kommentare unvoreingenommen.

Wir veröffentlichen feldspezifische Informationen zu den Reformen. Wir erhalten Feedback von einer anderen Gruppe von Menschen. Aufgrund der Themen, mit denen wir uns beschäftigen, kommen die Kommentare von normalen Menschen, Experten, einschließlich Staatsbeamten, unabhängigen und ausländischen. Ich sollte sagen, dass die usbekische Gesellschaft jetzt in den sozialen Netzwerken sehr aktiv ist. Wenn wir also online publizieren, bekommen wir mehr Kommentare dazu. Wir haben Kritiker. Wir haben andere Journalisten, die uns sagen, wir sollten uns mehr auf diese oder jene Information konzentrieren, die uns fehlt. Dafür sind wir offen. Und wir bewerten die Sinnhaftigkeit dieser Kommentare unvoreingenommen. Wenn sie vernünftig genug sind, machen wir weiter und füllen unsere Publikationen aus. Wenn sie angemessen sind, dann beziehen wir die mit ein in unsere Publikationen.

Abgesehen vom Internet sind wir auch bei öffentlichen Anhörungen präsent. In letzter Zeit haben wir mehrere öffentliche Anhörungen mit dem Justizministerium durchgeführt. Aktuell haben wir die Entwicklungspläne des Präsidenten für die Region Fergana vor Ort überprüft. Wir haben den stellvertretenden Gouverneur zu uns eingeladen und vorsprechen lassen. Aufgrund der großen Zahl an Zuschauer:innen sowie Zuschauer:innenfragen kam er mit einer großen Delegation. Er beantwortete alle unsere Fragen. Unsere Fragen zielten darauf ab herauszufinden, warum die Beamt:innen der Regionen bei der Durchführung von Reformen in bestimmten Schwerpunktbereichen versagt haben. Hierzu zählt die ursprünglich geplante Einführung von digitalen Plattformen und Programmen, insbesondere im medizinischen sowie Bildungsbereich - gerade in der Pandemie wäre beides sehr gefragt. Außerdem haben wir den Bericht der Rentenversicherung angehört, um sicherzustellen, dass alle Menschen ihre Pensionen korrekt sowie pünktlich erhalten.

Heute haben wir eine öffentliche Anhörung gemeinsam mit dem Gesundheitsministerium zum Thema Impfungen. Alle unsere Veranstaltungen sind live in den sozialen Netzwerken und im Fernsehen zu sehen. Wir sind uns der Tatsache bewusst, dass einige staatliche Kanäle nicht so populär sind wie die privaten. Deshalb versuchen wir zu diversifizieren und die beliebtesten zu bekommen, so wie heute. Heute wird der beliebte Sender UzReport live senden und zusätzlich auch in sozialen Netzwerken live übertragen. Ähnlich wie in anderen Ländern zögern auch in Usbekistan einige Menschen noch, sich impfen zu lassen. Wir sehen manchmal, dass das Tempo nicht so hoch ist, wie es sich die Regierung ursprünglich gewünscht hat. Daher arbeiten wir daran, so genaue Informationen wie möglich zu liefern. 
Daher versuchen wir Expert:innen, aber auch ganz unterschiedliche Staatsbedienstete, die für dieses Thema relevant sein können, zu engagieren.

Öffentliche Anhörungen helfen uns, kritisch an das Thema heranzugehen und kritisch zu bewerten, was Beamt:innen und die Regierung im Rahmen der Handlungsstrategie erreicht haben. Wenn diese Veröffentlichungen also Zahlen und Fakten zeigen, ermöglicht uns eine öffentliche Anhörung, die Informationen in mündlicher Form zu liefern. Das Gute daran ist, dass es aufgezeichnet wird und immer in unseren sozialen Netzwerken vorhanden ist, offen für unsere Leute, um Kritik zu üben oder Informationen zu erhalten. Wenn wir also sehen, dass es eine weitere Nachfrage gibt, ähnliche öffentliche Anhörungen durchzuführen, dann werden wir natürlich mehr tun.

\section{Wie erhalten Sie Ihr Feedback?}

Es gibt verschiedene Möglichkeiten, Feedback zu bekommen. Zum Beispiel laden wir so viele Mitglieder der Zivilgesellschaft und NGOs wie möglich zu unseren Veranstaltungen ein, weil sie es sind, die die Regierung am meisten kritisieren. Wenn wir Regierungsvertreter:innen einladen, kritisieren sie uns nicht. Sie sitzen nur und gehen. Daher versuchen wir, so viel wie möglich aus den Institutionen der Zivilgesellschaft einzuladen. Das ist eine Möglichkeit, direkt während der Veranstaltungen Feedback zu bekommen.

Weil wir oft Live-Veranstaltungen durchführen, bekommen wir auch Feedback aus den sozialen Netzwerken. So können die Leute kommentieren oder manchmal auch anrufen. Eine andere Möglichkeit, Feedback zu bekommen, ist unsere Institution. Sie ist offen, also klopfen die Leute an die Tür, bringen ihre Ansprüche und ihre Vorschläge mit.

Eine andere Möglichkeit, Feedback zu bekommen, sind natürlich unsere persönlichen Treffen mit den Menschen. Wir treffen uns regelmäßig mit Menschen in den Regionen, in sozialen Netzwerken oder während der Veranstaltungen.

Finden Sie, dass es genug Feedback von den Menschen gibt, mit denen Sie sprechen, und dass die Menschen merken, dass sie sich einbringen können, weil dies ein bedeutender Wandel vom »alten« zum »neuen« Usbekistan ist, dass die Leute merken, dass sie eine Stimme haben? Oder müssen Sie auf die Leute zugehen, um sie zu motivieren?

Um ehrlich zu sein, hat sich die Situation verändert. Die Menschen sind aktiver geworden, fordern mehr und interagieren sogar direkt mit dem Präsidenten. Natürlich ist er dann auch ein Vorbild. Er ist es, der die Regionen besucht und die Minister müssen ihm folgen, alle. Bei diesen Besuchen erhalten sie Feedback über ihre Arbeit, erhalten Kritik, werden mit Forderungen konfrontiert und erhalten auch konkrete Vorschläge für Verbesserungen. Das sind dann oft die Möglichkeiten, um Feedback zu erhalten und daran zu arbeiten.

$(\ldots)$

Wir sehen aber auch, dass wir nicht alle in den Prozess miteinbeziehen können. Es gibt immer noch Menschen, die dem Ganzen gleichgültig gegenüberstehen. »Ich will nicht in die Politik, lass mich damit in Ruhe, Politik ist nicht mein Thema, ich hab meine eigenen Probleme, (...) mir ist es egal was da vor sich geht.« Das sind auch Sätze, die wir von Zeit zu Zeit hören. Daher müssen wir als Staat auch Verbesserungsmöglichkeiten suchen, um mehr Menschen einzubeziehen. Der Präsident sagt aber, dass die Ideen für Reformen aus der Zivilgesellschaft kommen sollen. Die Zivilgesellschaft soll ein Initiator für Reformen sein. Leider nutzen dies nicht alle Menschen, auch wenn wir sehen, dass sich die Dinge in eine positive Richtung bewegen. Die Leute lassen sich immer mehr darauf ein. (...). 


\section{Die Verbreitung von Covid-19 in Zentralasien (Stand: 01. August 2021)}

Die Covid-19-Statistik wird nach dem Ende der Sommerpause eingestellt. Interessierte Leser_innen können sich über den Verlauf der Covid-19-Pandemie in Russland unter Verwendung entsprechender Filter auffolgenden Seiten im Internet informieren: https:// coronavirus.jhu.edu/map.html, https://github.com/CSSEGISandData/COVID-19/blob/master/csse_covid_19_data/csse_covid_19_ time_series/time_series_covid19_confirmed_global.csv, https://github.com/CSSEGISandData/COVID-19/blob/master/csse_ covid_19_data/csse_covid_19_time_series/time_series_covid19_deaths_global.csv, https://github.com/owid/covid-19-data/blob/ master/public/data/vaccinations/country_data/.

Bis zum 01.08.2021 lagen keine offiziellen oder bestätigten Meldungen über Fälle von Covid-19 in Turkmenistan vor.

Grafik 1: Ausbreitung von Covid-19 in Kasachstan* (tägliche Fallzahlen, 01. März 2020 - 01. August 2021)

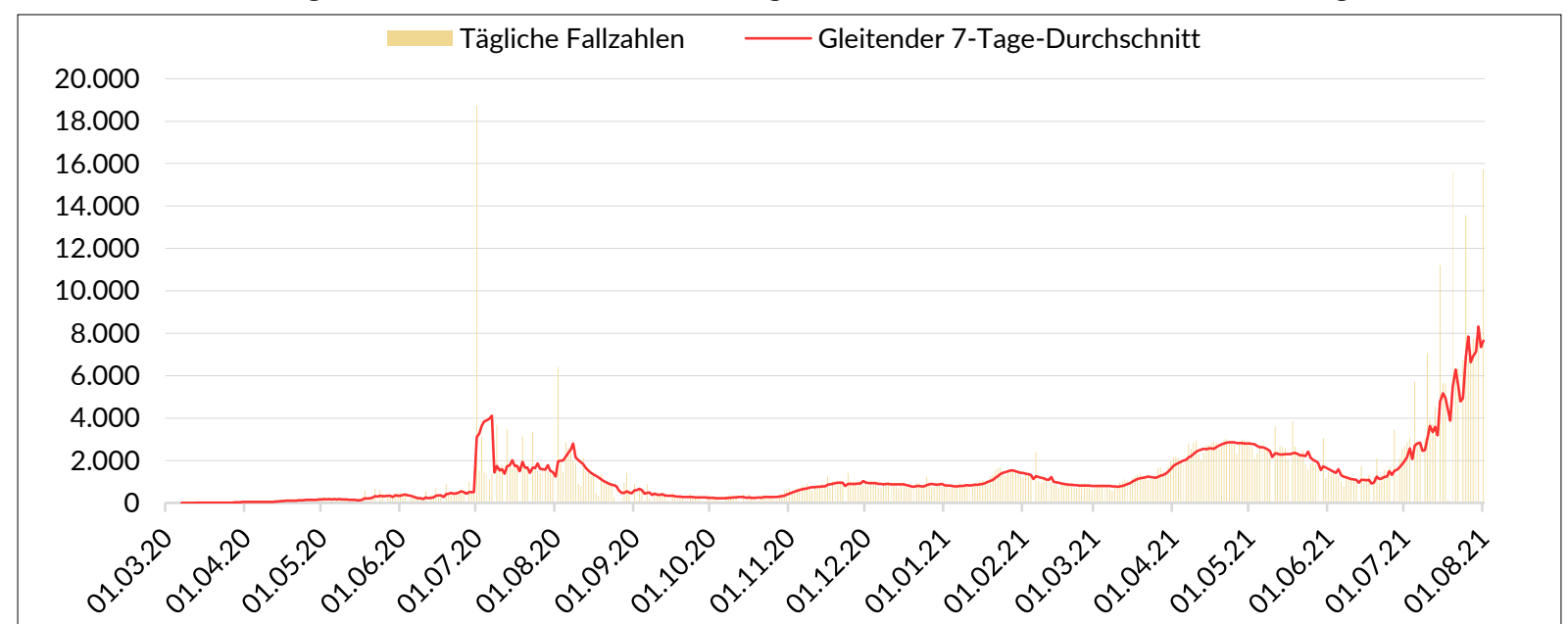

* Das Coronavirus Resource Center der Johns Hopkins University (JHU) gibt neuerdings nicht mehr die offiziell von der kasachstanischen Regierung veröffentlichte Gesamtzahl der Covid-19-Fälle wieder, sondern hat die wiedergegebenen Fallzahlen seit dem 02.08 .2020 eigenständig revidiert. Auf welcher Datengrundlage diese Revision erfolgte ist nicht ersichtlich. Die von der JHU wiedergegebenen Gesamtfallzahl ist seit dem 02.08 .2020 jeweils deutlich höher als die offizielle Gesamtfallzahl der kasachstanischen Regierung.

Die angegebenen Zahlen und Daten basieren auf den öffentlichen Angaben der jeweiligen Gesundheitsministerien. Der Wahrheitsgehalt ist umstritten und kann bezweifelt werden. Dennoch geben die Zahlen die öffentlich kommunizierte Einschätzung der epidemiologischen Lage der einzelnen Republiken wieder, weshalb wir uns als Redaktion entschlossen haben, sie an dieser Stelle zu veröffentlichen.

Quelle: Johns Hopkins Universität, Stand: 01.08.2021, 23:22 Uhr MESZ https://coronavirus.jhu.edu/map.html; https://github.com/CSSEGISandData/ COVID-19/blob/master/csse_covid_19_data/csse_covid_19_time_series/time_series_covid19_confirmed_global.csv

Grafik 2: Ausbreitung von Covid-19 in Kirgistan (tägliche Fallzahlen, 01. März 2020 - 01. August 2021)

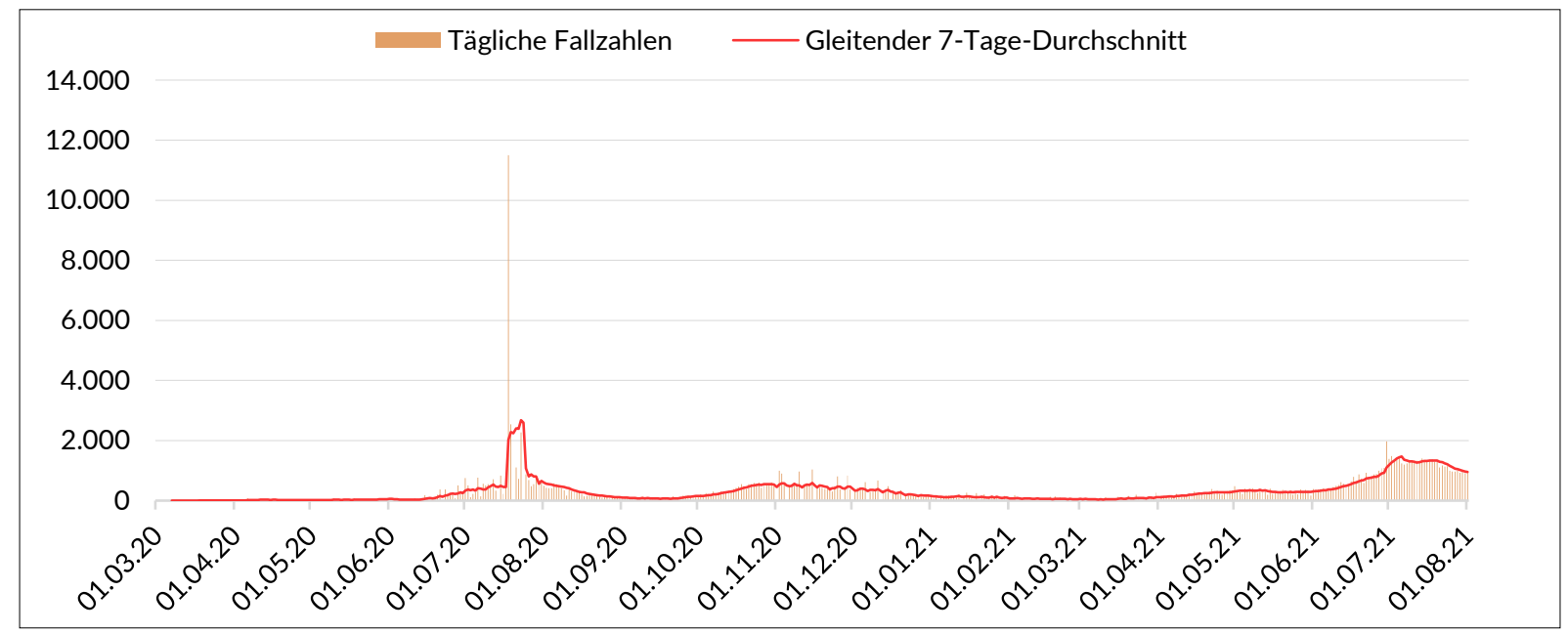

Die angegebenen Zahlen und Daten basieren auf den öffentlichen Angaben der jeweiligen Gesundheitsministerien. Der Wahrheitsgehalt ist umstritten und kann bezweifelt werden. Dennoch geben die Zahlen die öffentlich kommunizierte Einschätzung der epidemiologischen Lage der einzelnen Republiken wieder, weshalb wir uns als Redaktion entschlossen haben, sie an dieser Stelle zu veröffentlichen.

Quelle: Johns Hopkins Universität, Stand: 01.08.2021, 23:22 Uhr MESZ https://coronavirus.jhu.edu/map.html; https://github.com/CSSEGISandData/ COVID-19/blob/master/csse_covid_19_data/csse_covid_19_time_series/time_series_covid19_confirmed_global.csv 
Grafik 3: Ausbreitung von Covid-19 in Tadschikistan (tägliche Fallzahlen, 01. März 2020 - 01 . August 2021)

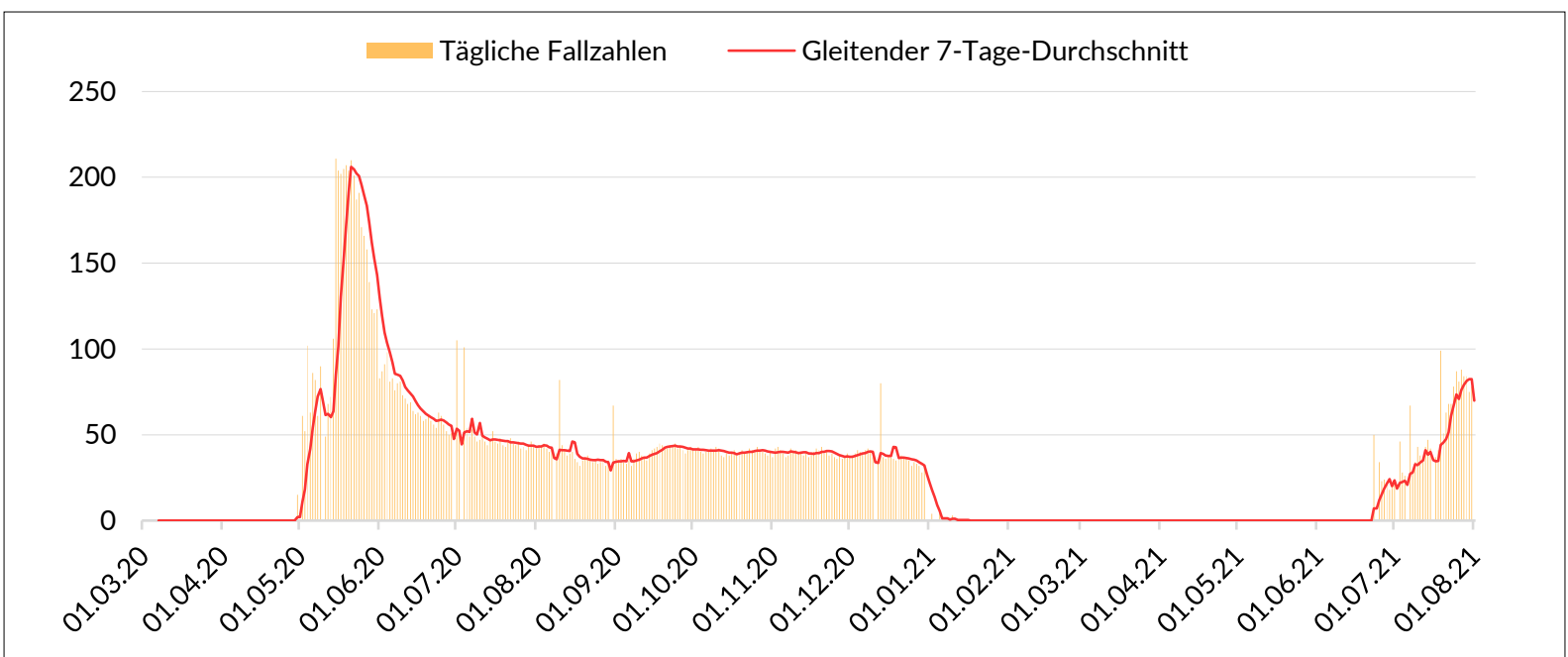

Die angegebenen Zahlen und Daten basieren auf den öffentlichen Angaben der jeweiligen Gesundheitsministerien. Der Wahrheitsgehalt ist umstritten und kann bezweifelt werden. Dennoch geben die Zahlen die öffentlich kommunizierte Einschätzung der epidemiologischen Lage der einzelnen Republiken wieder, weshalb wir uns als Redaktion entschlossen haben, sie an dieser Stelle zu veröffentlichen.

Quelle: Johns Hopkins Universität, Stand: 01.08.2021, 23:22 Uhr MESZ https://coronavirus.jhu.edu/map.html; https://github.com/CSSEGISandData/ COVID-19/blob/master/csse_covid_19_data/csse_covid_19_time_series/time_series_covid19_confirmed_global.csv

Grafik 4: Ausbreitung von Covid-19 in Usbekistan (tägliche Fallzahlen, 01. März 2020 - 01 . August 2021)

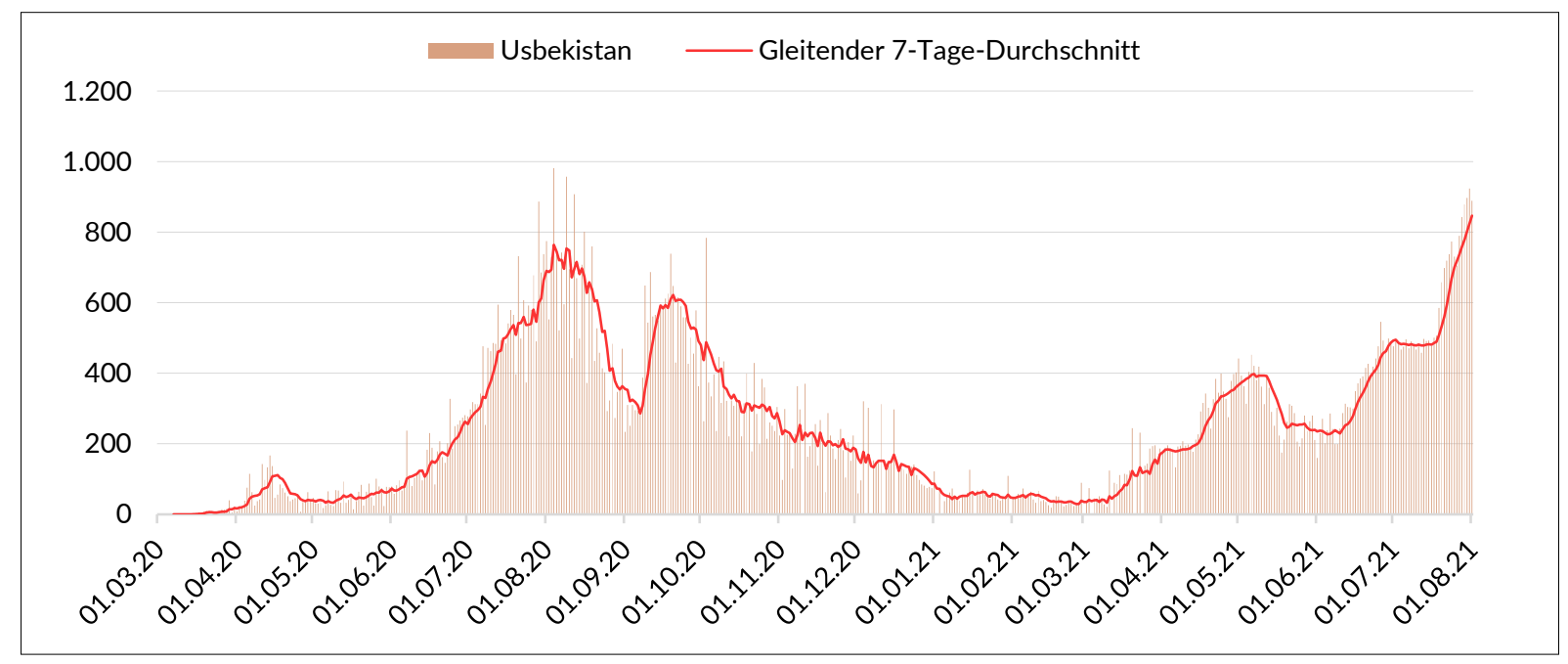

Die angegebenen Zahlen und Daten basieren auf den öffentlichen Angaben der jeweiligen Gesundheitsministerien. Der Wahrheitsgehalt ist umstritten und kann bezweifelt werden. Dennoch geben die Zahlen die öffentlich kommunizierte Einschätzung der epidemiologischen Lage der einzelnen Republiken wieder, weshalb wir uns als Redaktion entschlossen haben, sie an dieser Stelle zu veröffentlichen.

Quelle: Johns Hopkins Universität, Stand: 01.08.2021, 23:22 Uhr MESZ https://coronavirus.jhu.edu/map.html; https://github.com/CSSEGISandData/ COVID-19/blob/master/csse_covid_19_data/csse_covid_19_time_series/time_series_covid19_confirmed_global.csv 
Grafik 5: Todesfälle durch Covid-19 in Kasachstan* (tägliche Todesfälle, 01. März 2020 - 01. August 2021)

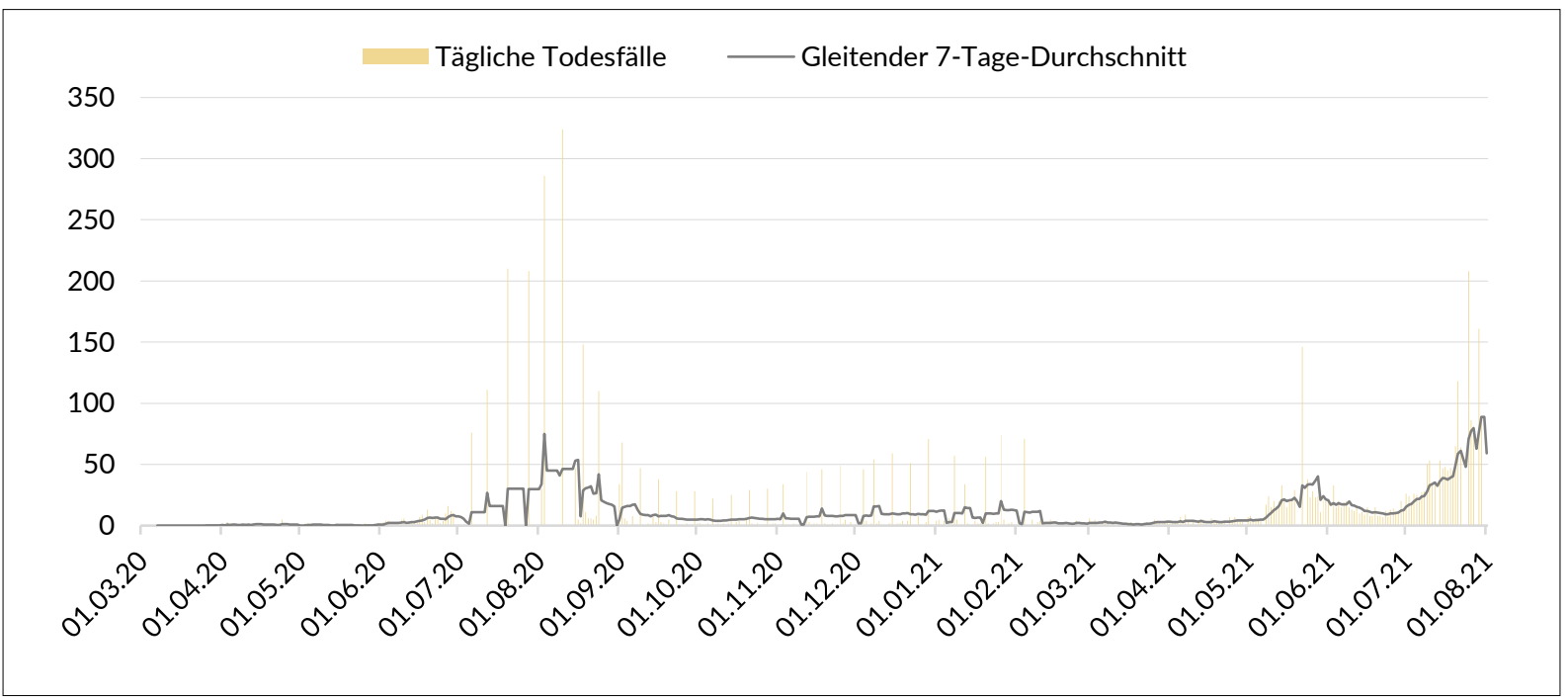

* Das Coronavirus Resource Center der Johns Hopkins University (JHU) gibt neuerdings nicht mehr die offiziell von der kasachstanischen Regierung veröffentlichte Gesamtzahl der Covid-19-Fälle wieder, sondern hat die wiedergegebenen Fallzahlen seit dem 02.08.2020 eigenständig revidiert. Auf welcher Datengrundlage diese Revision erfolgte ist nicht ersichtlich. Die von der JHU wiedergegebenen Gesamtfallzahl ist seit dem 02.08 .2020 jeweils deutlich höher als die offizielle Gesamtfallzahl der kasachstanischen Regierung.

Die angegebenen Zahlen und Daten basieren auf den öffentlichen Angaben der jeweiligen Gesundheitsministerien. Der Wahrheitsgehalt ist umstritten und kann bezweifelt werden. Dennoch geben die Zahlen die öffentlich kommunizierte Einschätzung der epidemiologischen Lage der einzelnen Republiken wieder, weshalb wir uns als Redaktion entschlossen haben, sie an dieser Stelle zu veröffentlichen.

Quelle: Johns Hopkins Universität, Stand: 01.08.2021, 23:22 Uhr MESZ https://coronavirus.jhu.edu/map.html; https://github.com/CSSEGISandData/ COVID-19/blob/master/csse_covid_19_data/csse_covid_19_time_series/time_series_covid19_confirmed_global.csv

Grafik 6: Todesfälle durch Covid-19 in Kirgistan* (tägliche Todesfälle, 01. März 2020 - 01 . August 2021)

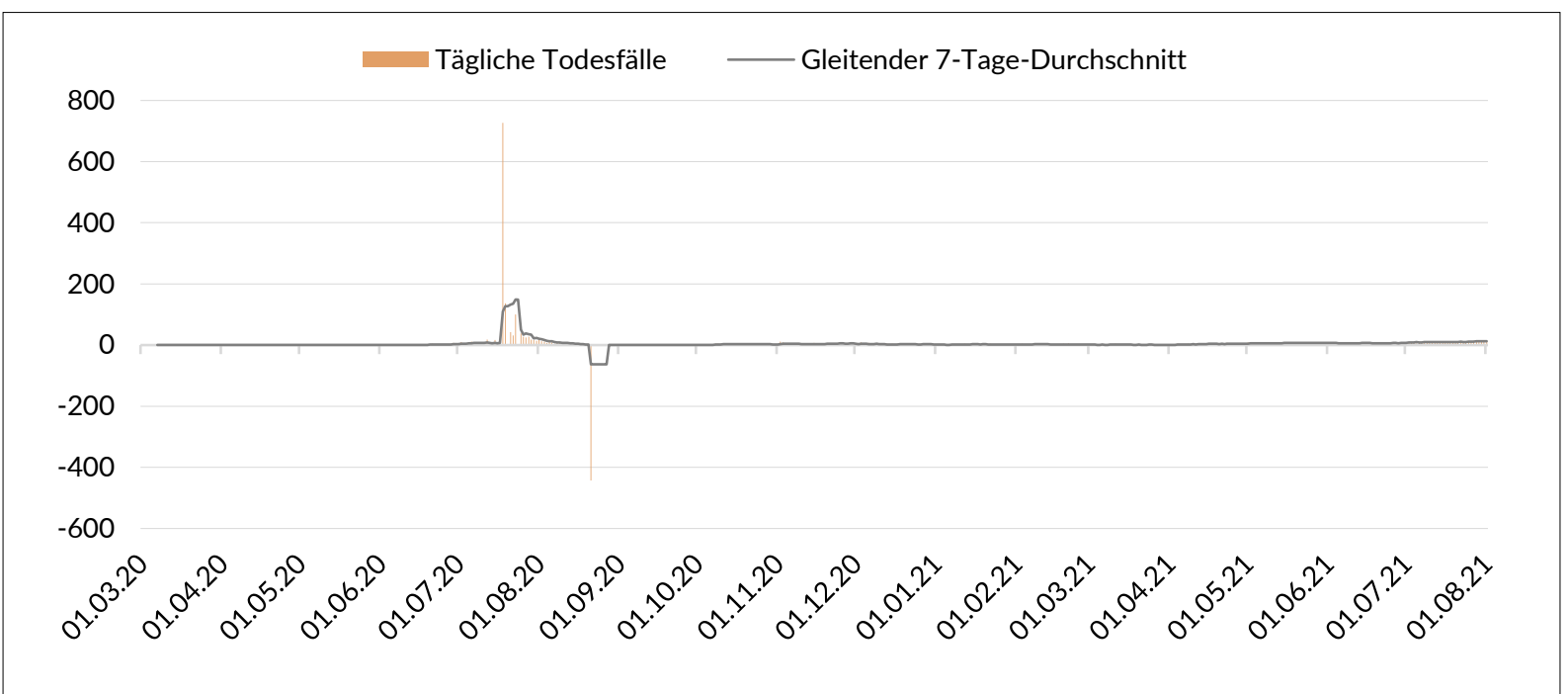

*Nach einer Revision der Covid-19-bedingten Todesfälle durch das Gesundheitsministerium Kirgistans wurde die Zahl am 18.08.2020 von 1.490 auf 1.053 korrigiert. U. a. wurden Todesfälle in Zusammenhang mit Herzinfarkten, Schlaganfällen und Nierenversagen, die nicht auf eine Covid-19-Erkrankung zurückgeführt werden konnten, aus der Statistik entfernt.

Die angegebenen Zahlen und Daten basieren auf den öffentlichen Angaben der jeweiligen Gesundheitsministerien. Der Wahrheitsgehalt ist umstritten und kann bezweifelt werden. Dennoch geben die Zahlen die öffentlich kommunizierte Einschätzung der epidemiologischen Lage der einzelnen Republiken wieder, weshalb wir uns als Redaktion entschlossen haben, sie an dieser Stelle zu veröffentlichen.

Quelle: Johns Hopkins Universität, Stand: 01.08.2021, 23:22 Uhr MESZ https://coronavirus.jhu.edu/map.html; https://github.com/CSSEGISandData/ COVID-19/blob/master/csse_covid_19_data/csse_covid_19_time_series/time_series_covid19_confirmed_global.csv 
Grafik 7: Todesfälle durch Covid-19 in Tadschikistan (tägliche Todesfälle, 01. März 2020 - 01. August 2021)

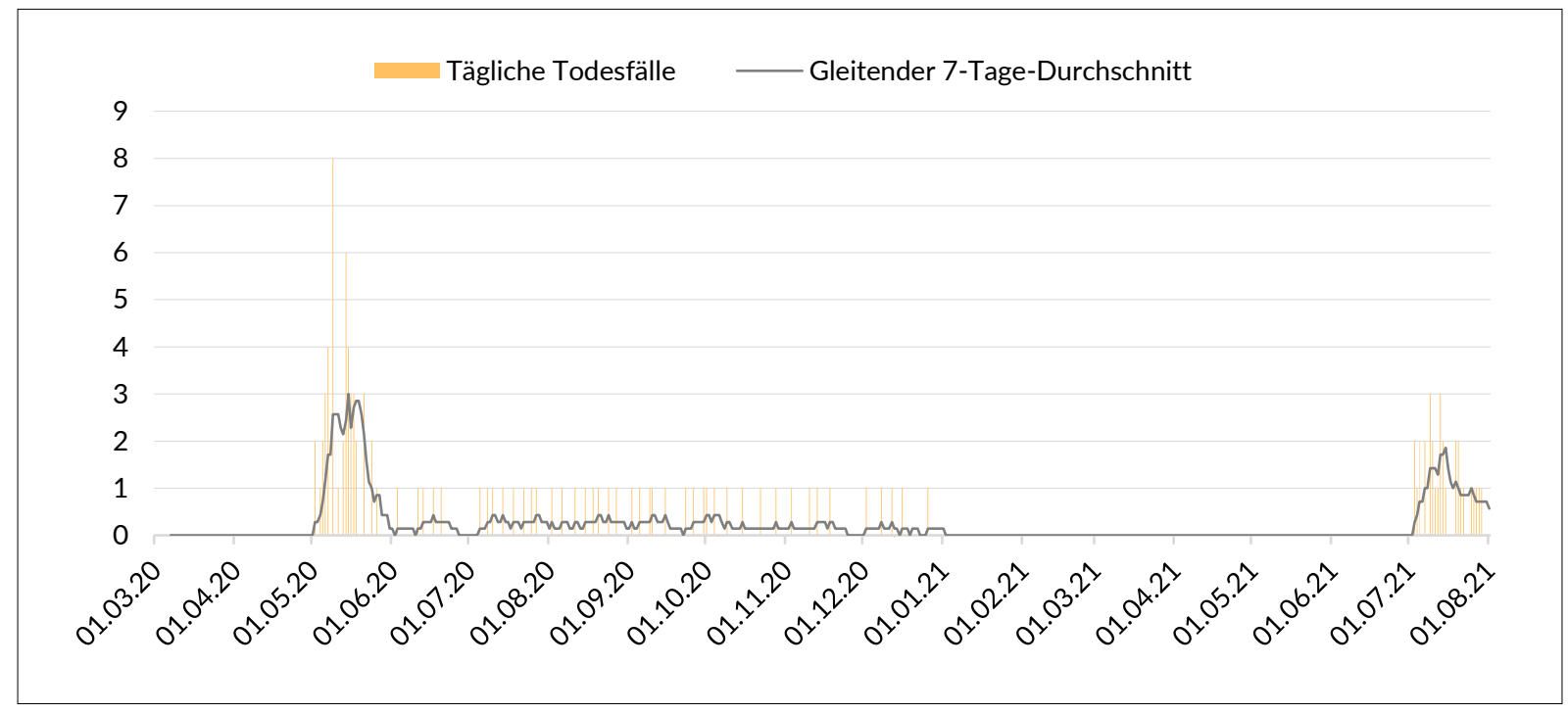

Die angegebenen Zahlen und Daten basieren auf den öffentlichen Angaben der jeweiligen Gesundheitsministerien. Der Wahrheitsgehalt ist umstritten und kann bezweifelt werden. Dennoch geben die Zahlen die öffentlich kommunizierte Einschätzung der epidemiologischen Lage der einzelnen Republiken wieder, weshalb wir uns als Redaktion entschlossen haben, sie an dieser Stelle zu veröffentlichen.

Quelle: Johns Hopkins Universität, Stand:01.08.2021, 23:22 Uhr MESZ https://coronavirus.jhu.edu/map.html; https://github.com/CSSEGISandData/ COVID-19/blob/master/csse_covid_19_data/csse_covid_19_time_series/time_series_covid19_confirmed_global.csv

Grafik 8: Todesfälle durch Covid-19 in Usbekistan (tägliche Todesfälle, 01. März 2020 - 01 . August 2021)

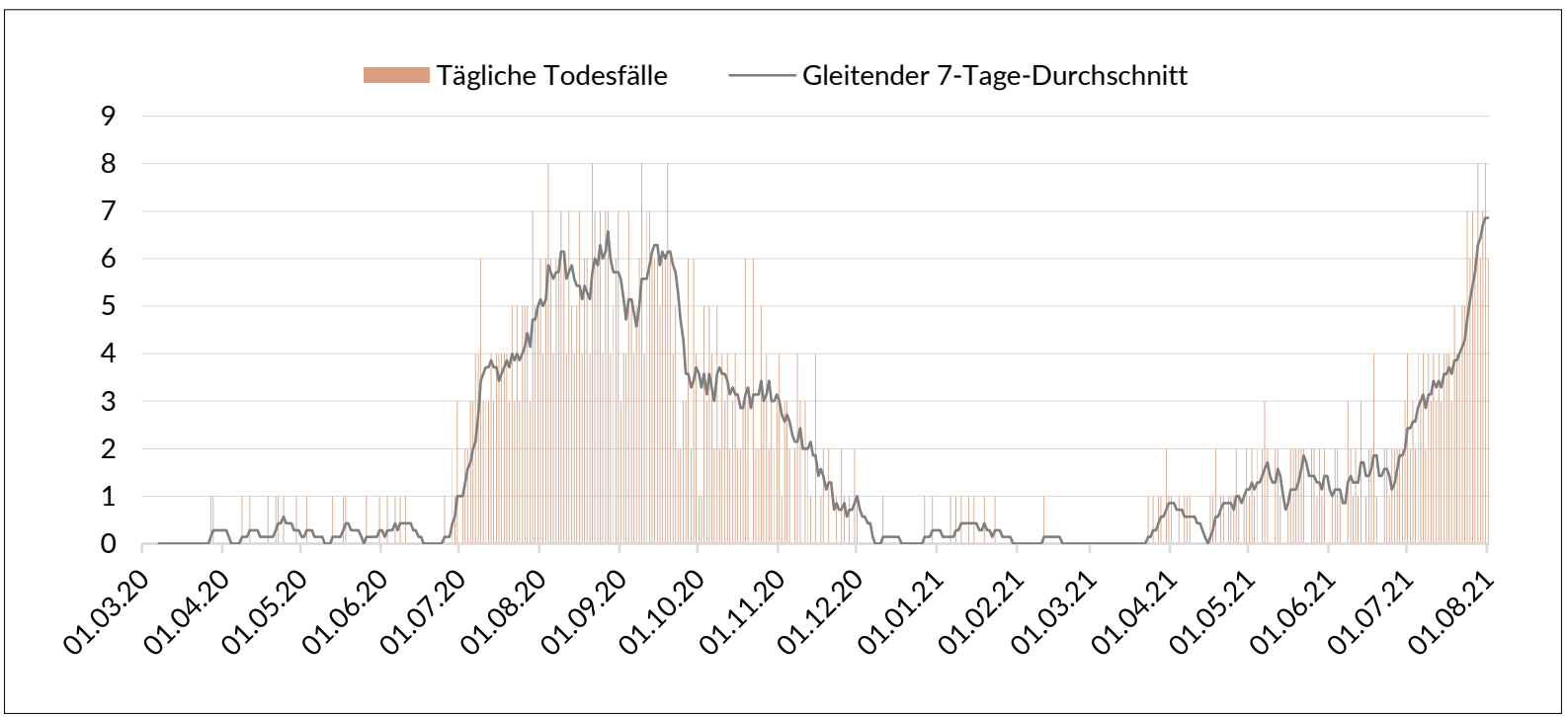

Die angegebenen Zahlen und Daten basieren auf den öffentlichen Angaben der jeweiligen Gesundheitsministerien. Der Wahrheitsgehalt ist umstritten und kann bezweifelt werden. Dennoch geben die Zahlen die öffentlich kommunizierte Einschätzung der epidemiologischen Lage der einzelnen Republiken wieder, weshalb wir uns als Redaktion entschlossen haben, sie an dieser Stelle zu veröffentlichen.

Quelle: Johns Hopkins Universität, Stand: 01.08.2021, 23:22 UhrMESZ https://coronavirus.jhu.edu/map.html; https://github.com/CSSEGISandData/ COVID-19/blob/master/csse_covid_19_data/csse_covid_19_time_series/time_series_covid19_confirmed_global.csv 
Grafik 9: Ausbreitung von Covid-19 in Zentralasien im Vergleich

(Fälle pro 100.000 Einwohner, 01. März 2020 - 01. August 2021)

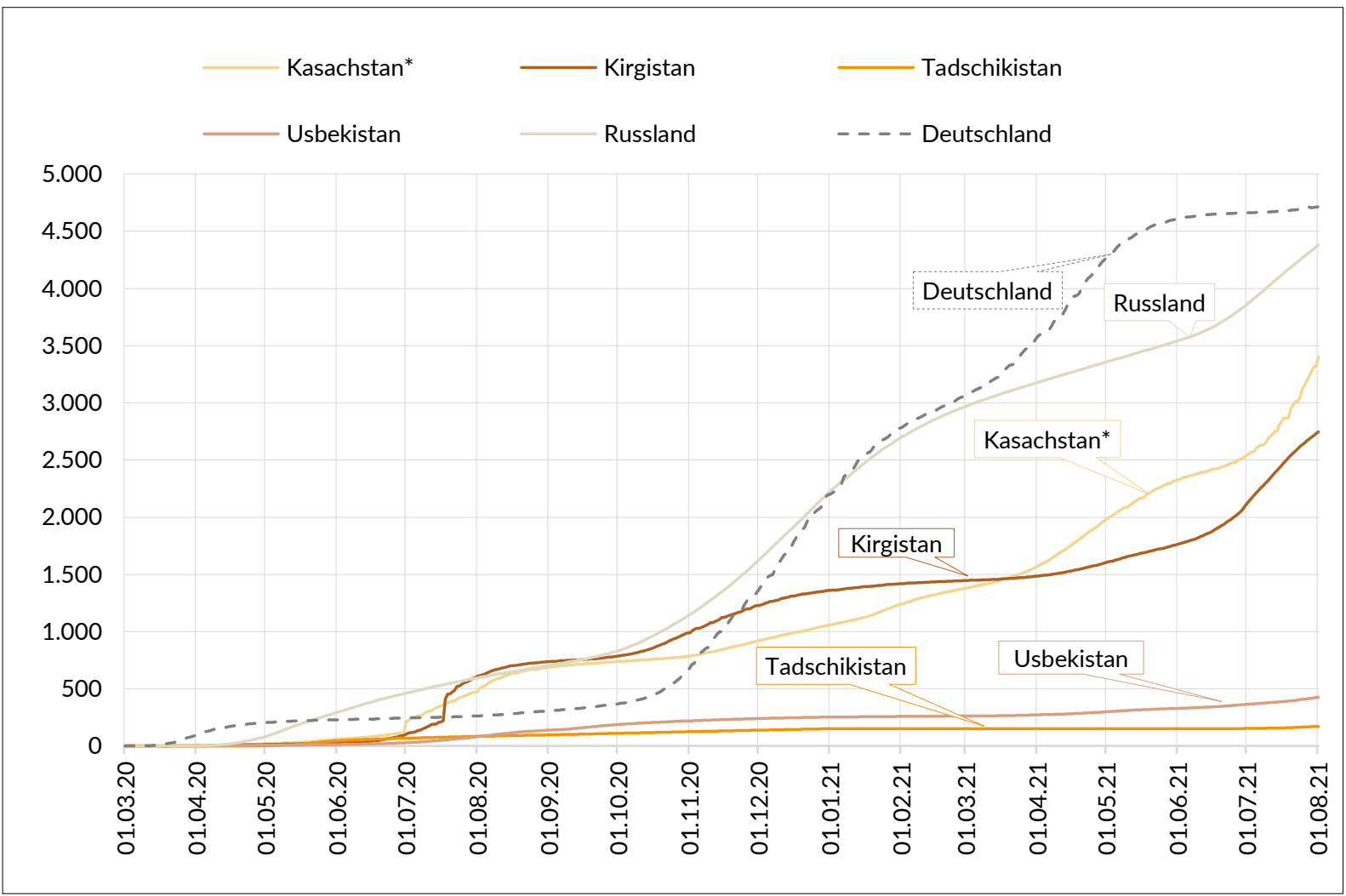

Bis zum 01.08.2021 lagen keine offiziellen oder bestätigten Meldungen über Fälle von Covid-19 in Turkmenistan vor.

* Das Coronavirus Resource Center der Johns Hopkins University (JHU) gibt neuerdings nicht mehr die offiziell von der kasachstanischen Regierung veröffentlichte Gesamtzahl der Covid-19-Fälle wieder, sondern hat die wiedergegebenen Fallzahlen seit dem 02.08.2020 eigenständig revidiert. Auf welcher Datengrundlage diese Revision erfolgte ist nicht ersichtlich. Die von der JHU wiedergegebenen Gesamtfallzahl ist seit dem 02.08.2020 jeweils deutlich höher als die offizielle Gesamtfallzahl der kasachstanischen Regierung.

Die angegebenen Zahlen und Daten basieren auf den öffentlichen Angaben der jeweiligen Gesundheitsministerien. Der Wahrheitsgehalt ist umstritten und kann bezweifelt werden. Dennoch geben die Zahlen die öffentlich kommunizierte Einschätzung der epidemiologischen Lage der einzelnen Republiken wieder, weshalb wir uns als Redaktion entschlossen haben, sie an dieser Stelle zu veröffentlichen.

Experten gehen davon aus, dass die offiziellen russischen Zahlen um ein Vielfaches zu niedrig ausfallen. Die Dunkelziffer kann im Fall der Todesfälle anhand der Übersterblichkeit geschätzt werden. Die/der Leser/in sei auch auf die Texte und Statistiken auf den S. 2-26 in den Russland-Analysen 400 (https:// www.laender-analysen.de/russland-analysen/400/) verwiesen .

Quelle: Johns Hopkins Universität, Stand: 01.08.2021, 23:22 Uhr MESZ https://coronavirus.jhu.edu/map.html; https://github.com/CSSEGISandData/ COVID-19/blob/master/csse_covid_19_data/csse_covid_19_time_series/time_series_covid19_confirmed_global.csv; Einwohnerzahlen: CIA World Factbook, https://www.cia.gov/the-world-factbook/ 
Grafik 10: Todesfälle durch Covid-19 in Zentralasien im Vergleich (Todesfälle pro 100.000 Einwohner, 01. März 2020 - 01. August 2021)

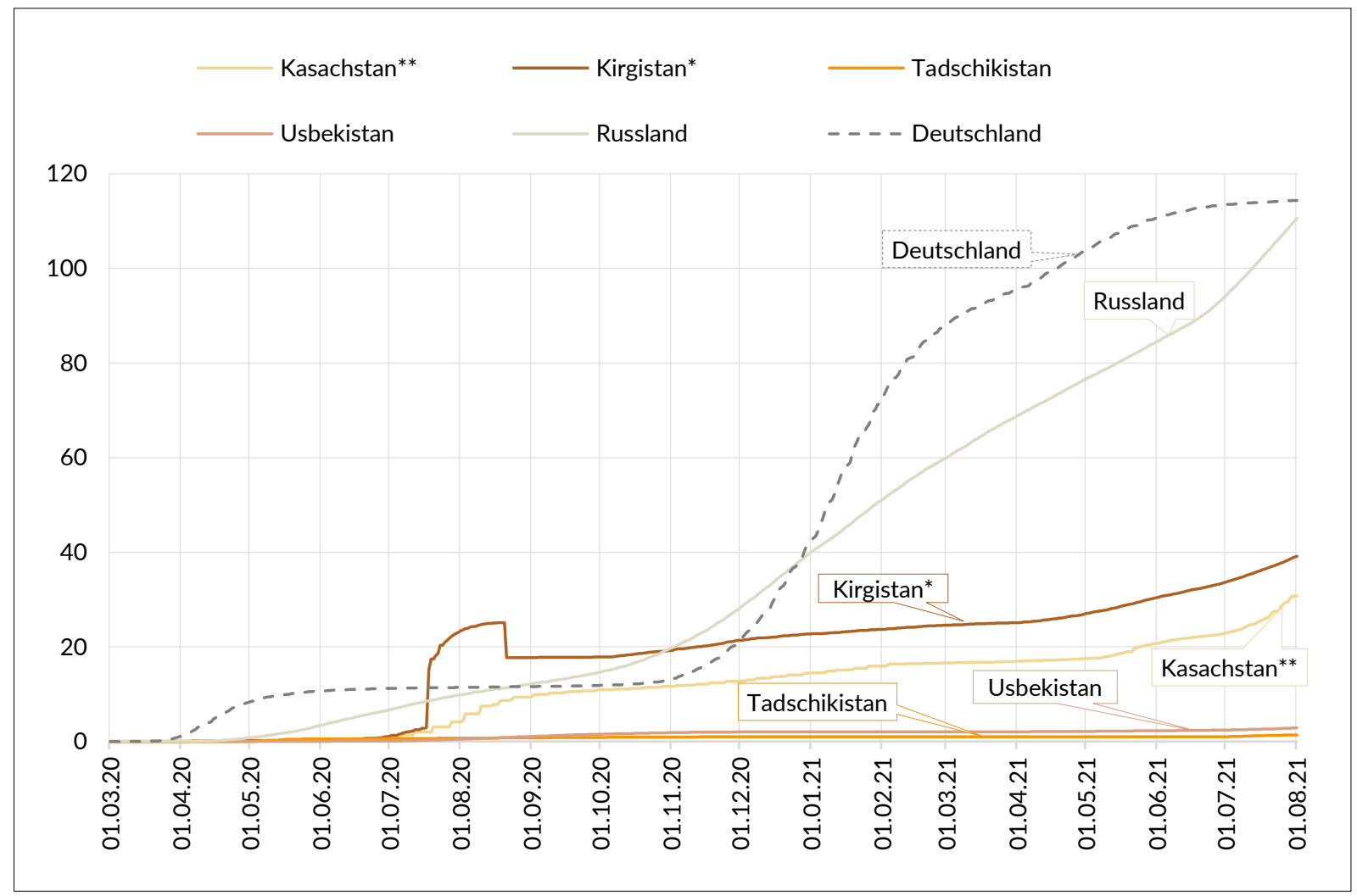

* Nach einer Revision der Covid-19-bedingten Todesfälle durch das Gesundheitsministerium Kirgistans wurde die Zahl am 18.08.2020 von 1.490 auf 1.053 korrigiert. U. a. wurden Todesfälle in Zusammenhang mit Herzinfarkten, Schlaganfällen und Nierenversagen, die nicht auf eine Covid-19-Erkrankung zurückgeführt werden konnten, aus der Statistik entfernt.

** Das Coronavirus Resource Center der Johns Hopkins University (JHU) gibt neuerdings nicht mehr die offiziell von der kasachstanischen Regierung veröffentlichte Gesamtzahl der Covid-19-Todesfälle wieder, sondern hat die wiedergegebenen Todesfallzahlen seit dem 02.08.2020 eigenständig revidiert. Auf welcher Datengrundlage diese Revision erfolgte ist nicht ersichtlich. Die von der JHU wiedergegebenen Gesamtfallzahl ist seit dem 02.08 .2020 jeweils deutlich höher als die offizielle Gesamtfallzahl der kasachstanischen Regierung.

Bis zum 01.08.2021 lagen keine offiziellen oder bestätigten Meldungen über Fälle von Covid-19 in Turkmenistan vor.

Die angegebenen Zahlen und Daten basieren auf den öffentlichen Angaben der jeweiligen Gesundheitsministerien. Der Wahrheitsgehalt ist umstritten und kann bezweifelt werden. Dennoch geben die Zahlen die öffentlich kommunizierte Einschätzung der epidemiologischen Lage der einzelnen Republiken wieder, weshalb wir uns als Redaktion entschlossen haben, sie an dieser Stelle zu veröffentlichen.

Experten gehen davon aus, dass die offiziellen russischen Zahlen um ein Vielfaches zu niedrig ausfallen. Die Dunkelziffer kann im Fall der Todesfälle anhand der Übersterblichkeit geschätzt werden. Die/der Leser/in sei auch auf die Texte und Statistiken auf den S. 2-26 in den Russland-Analysen 400 (https:// www.laender-analysen.de/russland-analysen/400/) verwiesen .

Quelle: Johns Hopkins Universität, Stand: 01.08.2021, 23:22 Uhr MESZ https://coronavirus.jhu.edu/map.html; https://github.com/CSSEGISandData/ COVID-19/blob/master/csse_covid_19_data/csse_covid_19_time_series/time_series_covid19_deaths_global.csv; Einwohnerzahlen: CIA World Factbook, https://www.cia.gov/the-world-factbook/ 
Tabelle 1: Ausbreitung von Covid-19 in Zentralasien im Vergleich (Fallzahlen, 15. Juni - 01. August 2021)

\begin{tabular}{|c|c|c|c|c|c|c|c|c|c|}
\hline Datum & $\begin{array}{l}\text { Kasach- } \\
\text { stan* }^{*}\end{array}$ & Kirgistan & $\begin{array}{l}\text { Tadschi- } \\
\text { kistan }\end{array}$ & $\begin{array}{l}\text { Usbe- } \\
\text { kistan }\end{array}$ & Datum & $\begin{array}{c}\text { Kasach- } \\
\text { stan* }^{*}\end{array}$ & Kirgistan & $\begin{array}{l}\text { Tadschi- } \\
\text { kistan }\end{array}$ & $\begin{array}{l}\text { Usbe- } \\
\text { kistan }\end{array}$ \\
\hline 15.06 .21 & 460.340 & 111.343 & 13.308 & 104.113 & 09.07.21 & 505.630 & 137.058 & 13.753 & 115.011 \\
\hline 16.06 .21 & 461.485 & 111.990 & 13.308 & 104.463 & 10.07.21 & 512.685 & 138.353 & 13.796 & 115.478 \\
\hline 17.06 .21 & 462.795 & 112.777 & 13.308 & 104.834 & 11.07.21 & 516.624 & 139.648 & 13.834 & 115.963 \\
\hline 18.06 .21 & 462.795 & 113.430 & 13.308 & 105.219 & 12.07.21 & 520.336 & 140.978 & 13.868 & 116.421 \\
\hline 19.06 .21 & 464.010 & 114.300 & 13.308 & 105.610 & 13.07 .21 & 524.878 & 142.270 & 13.911 & 116.918 \\
\hline 20.06 .21 & 466.125 & 115.030 & 13.308 & 106.025 & 14.07.21 & 524.878 & 143.668 & 13.958 & 117.409 \\
\hline 21.06 .21 & 467.069 & 115.615 & 13.308 & 106.452 & 15.07 .21 & 536.089 & 144.958 & 14.000 & 117.902 \\
\hline 22.06 .21 & 468.398 & 116.546 & 13.308 & 106.847 & 16.07.21 & 541.747 & 146.292 & 14.000 & 118.380 \\
\hline 23.06 .21 & 469.975 & 117.284 & 13.358 & 107.266 & 17.07.21 & 547.386 & 147.656 & 14.037 & 118.881 \\
\hline 24.06 .21 & 471.498 & 118.106 & 13.358 & 107.708 & 18.07.21 & 547.510 & 149.029 & 14.078 & 119.388 \\
\hline 25.06 .21 & 473.228 & 118.981 & 13.392 & 108.184 & 19.07.21 & 547.510 & 150.316 & 14.177 & 119.973 \\
\hline 26.06 .21 & 473.282 & 119.873 & 13.415 & 108.730 & 20.07 .21 & 563.173 & 151.607 & 14.228 & 120.631 \\
\hline 27.06 .21 & 476.740 & 120.865 & 13.439 & 109.223 & 21.07.21 & 568.915 & 152.709 & 14.291 & 121.329 \\
\hline 28.06 .21 & 478.063 & 121.946 & 13.460 & 109.692 & 22.07 .21 & 575.267 & 153.878 & 14.359 & 122.048 \\
\hline 29.06 .21 & 480.162 & 123.038 & 13.478 & 110.190 & 23.07.21 & 575.267 & 155.005 & 14.427 & 122.786 \\
\hline 30.06 .21 & 482.686 & 125.003 & 13.499 & 110.677 & 24.07.21 & 582.013 & 156.152 & 14.505 & 123.559 \\
\hline 01.07 .21 & 485.352 & 126.395 & 13.523 & 111.153 & 25.07 .21 & 595.577 & 157.147 & 14.592 & 124.290 \\
\hline 02.07 .21 & 488.204 & 127.880 & 13.523 & 111.648 & 26.07 .21 & 602.397 & 158.120 & 14.673 & 124.995 \\
\hline 03.07 .21 & 491.277 & 129.232 & 13.569 & 112.130 & 27.07.21 & 609.646 & 159.089 & 14.761 & 125.784 \\
\hline 04.07 .21 & 491.277 & 130.633 & 13.597 & 112.597 & 28.07.21 & 617.387 & 160.085 & 14.845 & 126.627 \\
\hline 05.07 .21 & 497.008 & 132.070 & 13.623 & 113.072 & 29.07.21 & 625.165 & 161.015 & 14.929 & 127.506 \\
\hline 06.07 .21 & 499.755 & 133.303 & 13.623 & 113.568 & 30.07 .21 & 633.469 & 161.973 & 15.004 & 128.403 \\
\hline 07.07 .21 & 502.581 & 134.501 & 13.690 & 114.039 & 31.07 .21 & 633.469 & 162.892 & 15.082 & 129.327 \\
\hline 08.07.21 & 502.581 & 135.739 & 13.719 & 114.529 & 01.08 .21 & 649.207 & 163.846 & 15.082 & 130.216 \\
\hline
\end{tabular}

Bis zum 01.08.2021 lagen keine offiziellen oder bestätigten Meldungen über Fälle von Covid-19 in Turkmenistan vor.

${ }^{*}$ Das Coronavirus Resource Center der Johns Hopkins University (JHU) gibt neuerdings nicht mehr die offiziell von der kasachstanischen Regierung veröffentlichte Gesamtzahl der Covid-19-Fälle wieder, sondern hat die wiedergegebenen Fallzahlen seit dem 02.08.2020 eigenständig revidiert. Auf welcher Datengrundlage diese Revision erfolgte ist nicht ersichtlich. Die von der JHU wiedergegebenen Gesamtfallzahl ist seit dem 02.08 .2020 jeweils deutlich höher als die offizielle Gesamtfallzahl der kasachstanischen Regierung.

Die angegebenen Zahlen und Daten basieren auf den öffentlichen Angaben der jeweiligen Gesundheitsministerien. Der Wahrheitsgehalt ist umstritten und kann bezweifelt werden. Dennoch geben die Zahlen die öffentlich kommunizierte Einschätzung der epidemiologischen Lage der einzelnen Republiken wieder, weshalb wir uns als Redaktion entschlossen haben, sie an dieser Stelle zu veröffentlichen.

Für die Zahlen vom 01.03.2020-14.06.2021 siehe Zentralasien-Analysen 140-147.

Quelle: Johns Hopkins Universität, Stand: 01.08.2021, 23:22 Uhr MESZ https://coronavirus.jhu.edu/map.html; https://github.com/CSSEGISandData/COVID-19/blob/master/csse_covid_19_data/csse_covid_19_time_series/time_series_covid19_confirmed_global.csv/ 
Tabelle 2: Todesfälle durch Covid-19 in Zentralasien im Vergleich (Gesamtzahl der Todesfälle, 15. Juni - 01. August 2021)

\begin{tabular}{|c|c|c|c|c|}
\hline Datum & $\begin{array}{c}\text { Kasach- } \\
\text { stan** }\end{array}$ & $\begin{array}{c}\text { Kir- } \\
\text { gistan* }\end{array}$ & $\begin{array}{c}\text { Tadschi- } \\
\text { kistan }\end{array}$ & $\begin{array}{c}\text { Usbe- } \\
\text { kistan }\end{array}$ \\
\hline 15.06 .21 & 4.180 & 1.905 & 90 & 709 \\
\hline 16.06 .21 & 4.195 & 1.912 & 90 & 711 \\
\hline 17.06 .21 & 4.203 & 1.916 & 90 & 713 \\
\hline 18.06 .21 & 4.211 & 1.920 & 90 & 717 \\
\hline 19.06 .21 & 4.226 & 1.925 & 90 & 718 \\
\hline 20.06 .21 & 4.234 & 1.931 & 90 & 718 \\
\hline 21.06 .21 & 4.242 & 1.937 & 90 & 718 \\
\hline 22.06 .21 & 4.249 & 1.945 & 90 & 720 \\
\hline 23.06 .21 & 4.261 & 1.953 & 90 & 722 \\
\hline 24.06 .21 & 4.268 & 1.958 & 90 & 723 \\
\hline 25.06 .21 & 4.281 & 1.964 & 90 & 725 \\
\hline 26.06 .21 & 4.295 & 1.971 & 90 & 727 \\
\hline 27.06 .21 & 4.306 & 1.977 & 90 & 729 \\
\hline 28.06 .21 & 4.316 & 1.982 & 90 & 731 \\
\hline 29.06 .21 & 4.336 & 1.992 & 90 & 733 \\
\hline 30.06 .21 & 4.349 & 2.000 & 90 & 736 \\
\hline 01.07 .21 & 4.375 & 2.009 & 90 & 740 \\
\hline 02.07 .21 & 4.399 & 2.019 & 90 & 742 \\
\hline 03.07 .21 & 4.418 & 2.027 & 92 & 745 \\
\hline 04.07 .21 & 4.444 & 2.037 & 93 & 747 \\
\hline 05.07 .21 & 4.469 & 2.046 & 95 & 751 \\
\hline 06.07 .21 & 4.489 & 2.054 & 95 & 754 \\
\hline 07.07 .21 & 4.516 & 2.063 & 97 & 758 \\
\hline 08.07 .21 & 4.544 & 2.073 & 97 & 760 \\
\hline & & 90 \\
\hline
\end{tabular}

\begin{tabular}{|c|c|c|c|c|}
\hline Datum & $\begin{array}{c}\text { Kasach- } \\
\text { stan** }\end{array}$ & $\begin{array}{c}\text { Kir- } \\
\text { gistan* }\end{array}$ & $\begin{array}{c}\text { Tadschi- } \\
\text { kistan }\end{array}$ & $\begin{array}{c}\text { Usbe- } \\
\text { kistan }\end{array}$ \\
\hline 09.07 .21 & 4.594 & 2.083 & 100 & 764 \\
\hline 10.07 .21 & 4.647 & 2.093 & 102 & 767 \\
\hline 11.07 .21 & 4.681 & 2.102 & 103 & 771 \\
\hline 12.07 .21 & 4.716 & 2.113 & 104 & 774 \\
\hline 13.07 .21 & 4.716 & 2.123 & 107 & 778 \\
\hline 14.07 .21 & 4.769 & 2.133 & 109 & 781 \\
\hline 15.07 .21 & 4.816 & 2.143 & 110 & 785 \\
\hline 16.07 .21 & 4.864 & 2.154 & 110 & 789 \\
\hline 17.07 .21 & 4.909 & 2.165 & 110 & 793 \\
\hline 18.07 .21 & 4.956 & 2.175 & 110 & 796 \\
\hline 19.07 .21 & 4.997 & 2.186 & 112 & 801 \\
\hline 20.07 .21 & 5.062 & 2.196 & 114 & 805 \\
\hline 21.07 .21 & 5.180 & 2.205 & 115 & 809 \\
\hline 22.07 .21 & 5.244 & 2.217 & 116 & 814 \\
\hline 23.07 .21 & 5.244 & 2.227 & 116 & 819 \\
\hline 24.07 .21 & 5.244 & 2.238 & 116 & 826 \\
\hline 25.07 .21 & 5.452 & 2.249 & 117 & 832 \\
\hline 26.07 .21 & 5.538 & 2.261 & 118 & 839 \\
\hline 27.07 .21 & 5.619 & 2.275 & 119 & 845 \\
\hline 28.07 .21 & 5.619 & 2.288 & 120 & 853 \\
\hline 29.07 .21 & 5.780 & 2.301 & 121 & 859 \\
\hline 30.07 .21 & 5.866 & 2.311 & 121 & 866 \\
\hline 31.07 .21 & 5.866 & 2.325 & 121 & 874 \\
\hline 01.08 .21 & 5.866 & 2.335 & 121 & 880 \\
\hline & & & & \\
\hline
\end{tabular}

* Nach einer Revision der Covid-19-bedingten Todesfälle durch das Gesundheitsministerium Kirgistans wurde die Zahl am 18.08.2020 von 1.490 auf 1.053 korrigiert. U. a. wurden Todesfälle in Zusammenhang mit Herzinfarkten, Schlaganfällen und Nierenversagen, die nicht auf eine Covid-19-Erkrankung zurückgeführt werden konnten, aus der Statistik entfernt.

** Das Coronavirus Resource Center der Johns Hopkins University (JHU) gibt neuerdings nicht mehr die offiziell von der kasachstanischen Regierung veröffentlichte Gesamtzahl der Covid-19-Todesfälle wieder, sondern hat die wiedergegebenen Todesfallzahlen seit dem 02.08.2020 eigenständig revidiert. Auf welcher Datengrundlage diese Revision erfolgte ist nicht ersichtlich. Die von der JHU wiedergegebenen Gesamtfallzahl ist seit dem 02.08 .2020 jeweils deutlich höher als die offizielle Gesamtfallzahl der kasachstanischen Regierung.

Bis zum 01.08.2021 lagen keine offiziellen oder bestätigten Meldungen über Fälle von Covid-19 in Turkmenistan vor.

Auch wenn die Zahlen alle aus einer Quelle stammen, sind sie nur begrenzt vergleichbar, da sich zwischen den Ländern der Umfang der Tests und die Erfassung von Covid-19 als Todesursache teilweise deutlich unterscheiden.

Für die Zahlen vom 26.03.2020-14.06.2021 siehe Zentralasien-Analysen 142-147.

Quelle: Johns Hopkins Universität, Stand: 01.08.2021, 23:22 Uhr MESZ https://coronavirus.jhu.edu/map.html; https://github.com/CSSEGISandData/COVID-19/blob/master/csse_covid_19_data/csse_covid_19_time_series/time_series_covid19_deaths_global.csv 


\section{Grafik 11: Gesamtzahl der Impfungen gegen Covid-19 in Kasachstan, Kirgistan, Tadschikistan, Turkmenistan} und Usbekistan (siehe Quellenangabe für die Daten)

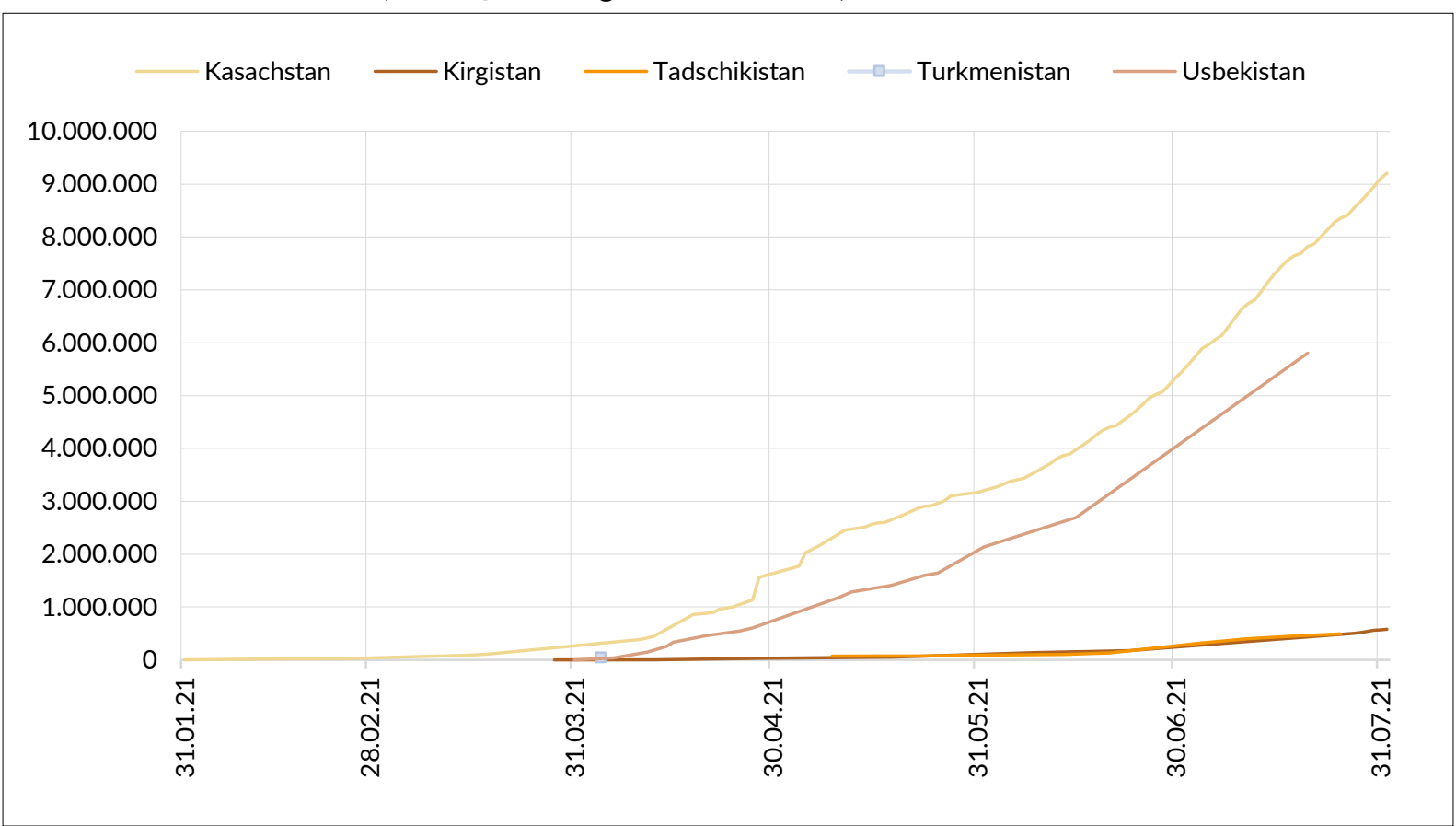

Verwendete Impfstoffe: Kasachstan: QazVac, Sinopharm/HayatVax, Sputnik V; Kirgistan: Sinopharm/Beijing, Sputnik V; Tadschikistan: Oxford/AstraZeneca, Sinovac; Turkmenistan: EpiVacCorona, Oxford/AstraZeneca, Sinopharm/Beijing, Sputnik V; Usbekistan: Oxford/AstraZeneca, RBD-Dimer, Sputnik V Quellen: https://github.com/owid/covid-19-data/tree/master/public/data/vaccinations/country_data; auf dieser Seite werden folgende Quellen angegeben: für Kasachstan (11.02.-01.08.201): https://www.aljazeera.com/news/2020/12/23/qatar-begins-coronavirus-vaccination-campaign, https://ortcom.kz/ru/novosti/qazaqstanda-14-mynnan-astam-medicina-qyzmetkeri-egildi, https://www.inform.kz/en/kazakhstan-administerssecond-doses-of-covid-19-vaccine-to-over-2-000_a3757206, https://www.inform.kz/en/18-807-received-second-covid-19-vaccine-doses-inkazakhstan-so-far_a3764487, https://menafn.com/1101775696/Over-19-thou-received-two-COVID-19-vaccine-doses-in-Kazakhstan, https://t. me/coronavirus2020_kz; für Kirgistan (06.04.-01.08.2021): https://24.kg/obschestvo/187924_pervyiy_poshel_ministr_zdravoohraneniya_ poluchil_privivku_otCOVID-19/, http://med.kg/en/news/4278-dmmp-people-who-received-covid-19-vaccine-are-feeling-well-and-report-nocomplaints.html, https://kloop.kg/blog/2021/04/07/kak-prohodit-vaktsinatsiya-v-kyrgyzstane-mozhno-li-uzhe-sejchas-poluchit-privivku-otcovid-19-obyasnyaem/amp/, https://eurasianet.org/dashboard-vaccinating-eurasia-april, http://www.xinhuanet.com/english/asiapacific/202105/11/c_139938939.htm, https://akipress.com/news:658330:Kyrgyzstan_vaccinates_over_54,100_against_COVID-19/, https://akipress.com/ news:659241:Kyrgyzstan vaccinates_over 88,000_against_COVID-19/, https://akipress.com/news:659779:Kyrgyzstan_vaccinates 99,900 against_COVID-19_so_far/, https://vc.emed.gov.kg/; für Tadschikistan (09.05.-25.07.2021) und Turkmenistan (04.04.2021): https://covid19.who. int/, https://www.euro.who.int/en/covid19dashboard; für Usbekistan (06.04.-20.07.2021): https://eurasianet.org/dashboard-vaccinating-eurasiaapril, https://www.uzdaily.uz/en/post/64774, https://uzreport.news/society/almost-257-000-uzbek-citizens-receive-coronavirus-vaccine, https:// www.uzdaily.uz/en/post/64882, https://tashkenttimes.uz/national/6790-450-thousand-people-vaccinated-as-of-april-21, https://en.trend. az/casia/uzbekistan/3414814.html, https://akipress.com/news:657419:Uzbekistan_vaccinates_600,369_against_COVID-19/, https://menafn. com/1102063291/Uzbekistan-reveals-number-of-vaccinated-people, https://kant.kg/2021-05-14/v-uzbekistane-ispolzovano-pochti-13-millionadoz-vakcziny-ot-koronavirusa/, https://kun.uz/en/news/2021/05/19/uzbekistan-receives-500-thousand-doses-of-sino-uzbek-vaccine, http:// zamon.uz/en/to-date-1-183-943-people-have-been-vaccinated-in-the-first-stage-and-416-561-people-have-been-vaccinated-in-the-secondstage-in-uzbekistan/, https://akipress.com/news:658590:Uzbekistan_vaccinates_over_1_642_million_against_COVID-19/, https://menafn. com/1102195511/Uzbekistan-reveals-number-of-vaccinated-citizens, https://akipress.com/news:659485:Uzbekistan_vaccinates_over_1_623_ million_against_COVID-19/, https://en.trend.az/casia/uzbekistan/3457917.html 
Grafik 12: Anteile der Gesamtbevölkerungen Kasachstans, Kirgistans, Tadschikistans, Turkmenistans und Usbekistans, die vollständig gegen Covid-19 geimpft sind, im Vergleich (Datum siehe Quellenangabe)

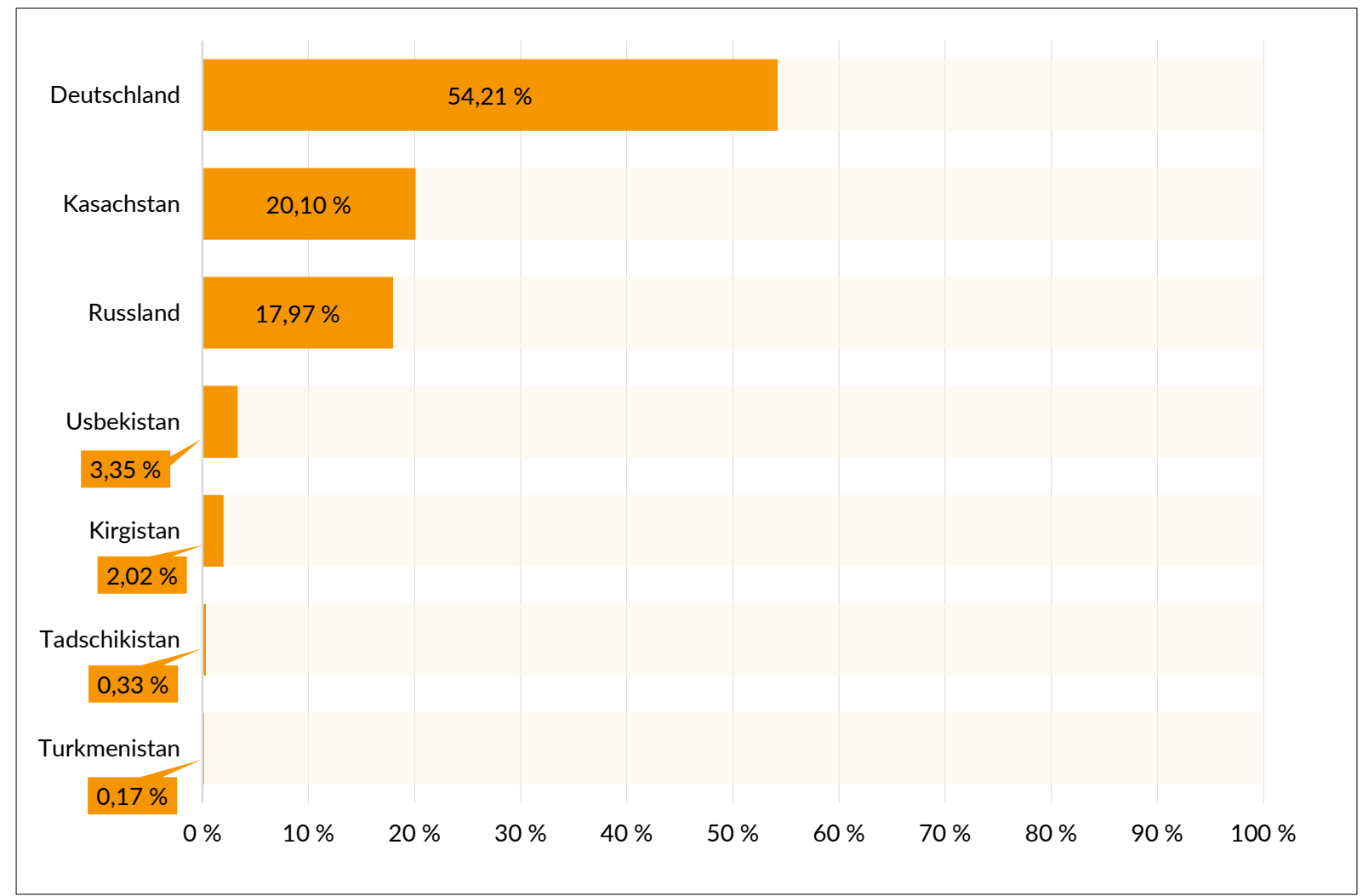

Quellen: https://github.com/owid/covid-19-data/tree/master/public/data/vaccinations/country_data; auf dieser Seite werden folgende Quellen angegeben: für Kasachstan (01.08.2021): https://www.coronavirus2020.kz/; für Kirgistan (01.08.2021): https://vc.emed.gov.kg/; für Tadschikistan (25.07.2021) und Turkmenistan (04.04.2021): https://covid19.who.int/; für Usbekistan (20.07.2021): https://en.trend.az/casia/uzbekistan/3457917. html; für Russland (01.08.2021): https://gogov.ru/articles/covid-v-stats; für Deutschland (01.08.2021): https://impfdashboard.de/. Quelle für die Bevölkerungszahlen: https://www.cia.gov/the-world-factbook/countries/ 
24. Mai-08. Juli 2021

(einschließlich Covid-19-Chronik)

Kasachstan

Die Chronik wird zeitnah erstellt und basiert ausschließlich auf im Internet frei zugänglichen Quellen. Die Redaktion bemüht sich, bei jeder Meldung die ursprüngliche Quelle eindeutig zu nennen. Aufgrund der großen Zahl von manipulierten und falschen Meldungen kann die Redaktion der Zentralasien-Analysen keine Gewähr für die Richtigkeit der Angaben übernehmen.

Zusammengestellt von Rostam Onsori und Richard Schmidt

Sie können die gesamte Chronik seit 2008 auch auf http://www.laender-analysen.de/zentralasien/ unter dem Link »Chronik«lesen. 


\begin{tabular}{|c|c|}
\hline 25.5.2021 & $\begin{array}{l}\text { Präsident Kasym-Dschomart Tokajew unterzeichnet eine Änderung des Wahlgesetzes. Künftig benötigen Par- } \\
\text { teien zum Einzug in das Parlament fünf Prozent der Stimmen, zuvor waren es sieben. }\end{array}$ \\
\hline 1.6.2021 & Laut Gesundheitsministerium hat Kasachstan 500.000 Dosen des chinesischen Impfstoffes »Sinovac« erhalten. \\
\hline 2.6 .2021 & $\begin{array}{l}\text { Das Parlament verabschiedet ein Gesetz, das Inländer:innen die Pacht kasachstanischer Agrarflächen von bis } \\
\text { zu } 49 \text { Jahren ermöglicht. }\end{array}$ \\
\hline 2.6.2021 & $\begin{array}{l}\text { In Nur-Sultan empfängt Präsident Tojakew den usbekischen Premierminister Abdulla Aripow. Beide Seiten } \\
\text { bekräftigen ihr Ziel, das bilaterale Handelsvolumen künftig auf } 10 \text { Mrd. US-Dollar zu erhöhen. }\end{array}$ \\
\hline 3.6.2021 & $\begin{array}{l}\text { Präsident Tokajew empfängt seinen armenischen Amtskollegen Armen Sarkissian zu Gesprächen in Nur-Sul- } \\
\text { tan. Beide Seiten planen ihre Zusammenarbeit auszubauen, u. a. in den Bereichen Wirtschaft und Handel } \\
\text { sowie im Rahmen von EAEU und CSTO. }\end{array}$ \\
\hline 3.6 .2021 & $\begin{array}{l}\text { Das Nationale Statistikamt beziffert die Gesamtbevölkerung Kasachstans, Stand 1.5.2021, auf 18.962.892 } \\
\text { Personen. }\end{array}$ \\
\hline 5.6 .2021 & $\begin{array}{l}\text { Nachdem Russland eine Diskussion über einheitliche Gegensanktionen von EAEU-Staaten gegen westliche } \\
\text { Staaten angeregt hat, wird sich Kasachstan (laut dem Außenministerium) nicht an Gegensanktionen beteili- } \\
\text { gen. Das Land lehne eine Politisierung der EAEU ab. }\end{array}$ \\
\hline 10.6 .2021 & $\begin{array}{l}\text { Präsident Tokajew unterzeichnet ein neues Gesetz, laut dem sich Anwält:innen künftig beim »Staatlichen } \\
\text { Anwaltskollegium» anmelden müssen, dessen Mitgliedschaft gebührenpflichtig ist. Kritiker:innen befürchten } \\
\text { das Gesetz könne die Unabhängigkeit von Anwält:innen untergraben. }\end{array}$ \\
\hline 11.6 .2021 & $\begin{array}{l}\text { In Nur-Sultan empfängt Premierminister Askar Mamin die emiratische Ministerin für Ernährungs- und } \\
\text { Wassersicherheit, Mariam Al-Muhairi. Beide Seiten einigen sich auf eine Vertiefung der Zusammenarbeit im } \\
\text { Bereich Lebensmittelproduktion. }\end{array}$ \\
\hline 14.6 .2021 & $\begin{array}{l}\text { In Nur-Sultan empfängt Präsident Tokajew den US-Sonderbeauftragte für Afghanistan, Zalmay Khalilzad. } \\
\text { Beide Seiten beraten u. a. über die weitere Entwicklung der bilateralen Partnerschaft im Rahmen des gemein- } \\
\text { samen Ziels, die Sicherheit und Stabilität Afghanistans zu fördern. }\end{array}$ \\
\hline 18.6 .2021 & $\begin{array}{l}\text { Außenminister Muchtar Tileuberdi und Verteidigungsminister Nurlan Jermekbajew empfangen den Natio- } \\
\text { nalen Sicherheitsberater Afghanistans, Hamdullah Mohib, in Nur-Sultan zu Gesprächen. Beide Seiten unter- } \\
\text { zeichnen ein Abkommen zum Ausbau der militärischen Zusammenarbeit. }\end{array}$ \\
\hline 28.6 .2021 & $\begin{array}{l}\text { In Nur-Sultan empfängt Präsident Tokajew den belarussischen Premierminister Roman Golowtschenko zu } \\
\text { Gesprächen. Beide Seiten bekräftigen den Wunsch nach Vertiefung der bilateralen Zusammenarbeit und unter- } \\
\text { zeichnen ein Übereinkommen, das die Belieferung von Belarus mit kasachstanischem Erdöl vorsieht. }\end{array}$ \\
\hline 30.6 .2021 & $\begin{array}{l}\text { Der Erste Präsident Nursultan Nasarbajew wird in Moskau vom russischen Präsidenten Wladimir Putin zu } \\
\text { Gesprächen empfangen. Beide Seiten erörtern u. a. Fragen der eurasischen Integration und der regionalen } \\
\text { Sicherheit, besonders im Hinblick auf die aktuelle Situation in Afghanistan. }\end{array}$ \\
\hline 1.7 .2021 & $\begin{array}{l}\text { Präsident Tokajew kündigt die Etablierung einer neuen Regierungskörperschaft für die Selbstverwaltung auf } \\
\text { der lokalen Ebene an. Die Kenester (»Räte«) sollen u. a. mit Befugnissen zur Anpassung von Steuern an die } \\
\text { lokalen sozioökonomischen Gegebenheiten ausgestattet sein. }\end{array}$ \\
\hline 7.7.2021 & $\begin{array}{l}\text { Human Rights Watch kritisiert die zunehmende Verfolgung von Regierungskritiker:innen in Kasachstan. } \\
\text { Laut HRW sind derzeit } 135 \text { Personen unrechtmäßiger Strafverfolgung ausgesetzt. Die staatlichen Repressio- } \\
\text { nen bedrohen auch zunehmend Teilnehmer:innen friedlicher Versammlungen. }\end{array}$ \\
\hline
\end{tabular}


Kirgistan 


\begin{tabular}{|c|c|}
\hline 24.5.2021 & $\begin{array}{l}\text { Präsident Sadyr Dschaparow wird im russischen Sotschi von seinem russischen Amtskollegen Wladimir Putin } \\
\text { zu Gesprächen über Fragen der Zusammenarbeit, u. a. im Rahmen der CSTO und im gemeinsamen Kampf } \\
\text { gegen Coivd-19, empfangen. Putin äußert, dass Russland die Situation an der kirgisisch-tadschikischen Grenze } \\
\text { genau beobachte und alle Bemühungen für eine friedliche Lösung des Konfliktes unterstütze. }\end{array}$ \\
\hline 24.5.2021 & $\begin{array}{l}\text { Akipress meldet, dass das Ministerkabinett bereits am 21.5.2021 ein temporäres Einreiseverbot für tadschiki- } \\
\text { sche Staatsbürger:innen erlassen hat, bis die Grenzspannungen mit Tadschikistan überwunden sind. }\end{array}$ \\
\hline 25.5.2021 & Am Flughafen Manas wird 177 tadschikischen Staatsbürgern die Einreise verweigert. \\
\hline 27.5.2021 & $\begin{array}{l}\text { Der ehemalige Bürgermeister von Bischkek, Asis Surakmatow, wird wegen des Verdachtes auf Korruption und } \\
\text { illegale Bereicherung festgenommen. }\end{array}$ \\
\hline 28.5.2021 & $\begin{array}{l}\text { Nachdem die Zentrale Wahlkommission (CEC) die Ergebnisse der am 11.4.2021 abgehaltenen Lokalwahlen } \\
\text { für Bischkek, Osch und Tokmok (Gebiet Tschui) annulliert hat, terminiert Präsident Dschaparow eine Wie- } \\
\text { derholung der Wahlen in diesen Städten auf den 11.7.2021. Die Ergebnisse wurden annulliert, nachdem die } \\
\text { CEC über } 400 \text { Hinweise auf Wahlverstößen in diesen Städten erhalten hat. }\end{array}$ \\
\hline 31.5.2021 & $\begin{array}{l}\text { Der ehemalige Premierminister Omurbek Babanow wird in Bischkek wegen des Verdachtes auf Korruption im } \\
\text { Zusammenhang mit der Kumtor-Goldmine (Gebiet Issyk-Kul) festgenommen. }\end{array}$ \\
\hline 1.6 .2021 & $\begin{array}{l}\text { Der Gouverneur des Gebietes Batken, Alimbajew, und sein Amtskollege des tadschikischen Gebietes Sughd, } \\
\text { Achmadzoda, einigen sich auf die Etablierung von gemeinsamen Fußpatrouillen entlang der internationalen } \\
\text { Grenze zwischen den Bezirken Ghafurow (Gebiet Sughd) und Lejlek (Gebiet Batken). }\end{array}$ \\
\hline 1.6 .2021 & $\begin{array}{l}\text { Orhan Inandi, Gründer der "Sapat«-Lyzeen, wird in Bischkek als vermisst gemeldet. Der türkisch-kirgisische } \\
\text { Staatsbürger Inandi gilt als Unterstützer der in der Türkei verbotenen Gülen-Bewegung. Vor der türkischen } \\
\text { Botschaft in Bischkek versammeln sich mehrere Dutzend Protestierende. }\end{array}$ \\
\hline 2.6 .2021 & $\begin{array}{l}\text { In Bischkek empfängt Präsident Dschaparow den EU-Sonderbeauftragten für Zentralasien, Peter Burian. } \\
\text { U. a. einigen sich beide Seiten darauf, dass erste EU-Zentralasien-Wirtschaftsforum im Herbst } 2021 \text { in Bisch- } \\
\text { kek auszurichten. }\end{array}$ \\
\hline 2.6.2021 & $\begin{array}{l}\text { Vor dem Regierungssitz in Bischkek verlangen über } 200 \text { Personen Informationen zum Verbleib von Orhan } \\
\text { Inandi. Die Demonstrationen halten mehrere Wochen an. Die Polizei leitet ein Strafermittlungsverfahren } \\
\text { wegen des Verdachtes auf Entführung ein. }\end{array}$ \\
\hline 5.6 .2021 & $\begin{array}{l}\text { Der GNKB-Vorsitzende Taschijew und sein tadschikischer Amtskollege Jatimow einigen sich nach einer } \\
\text { gemeinsamen Sitzung zu Grenzfragen auf ein Protokoll. Dieses sieht den Abzug aller regulären Truppen von } \\
\text { der Grenze, die Verrückung von Grenzposten drei Kilometer von der Grenze weg, sowie die Gestattung der } \\
\text { Nutzung von grenznahen Weideflächen vor. }\end{array}$ \\
\hline 10.6 .2021 & $\begin{array}{l}\text { In Ankara empfängt Präsident Recep Tayyip Erdoğan seinen kirgisischen Amtskollegen Dschaparow. Beide Sei- } \\
\text { ten planen das bilaterale Handelsvolumen auf mindestens } 1 \text { Mrd. US-Dollar zu verdoppeln. Im Gebiet Tschui } \\
\text { soll eine türkisch-kirgisische Industriezone entstehen. }\end{array}$ \\
\hline 17.6.2021 & $\begin{array}{l}\text { Das Parlament verabschiedet ein Gesetz, welches NGOs und gemeinnützige Organisationen dazu verpflichtet, } \\
\text { dem Staat Finanzierungsquellen und Ausgabenposten offenzulegen. }\end{array}$ \\
\hline 21.6 .2021 & $\begin{array}{l}\text { Am Rande des Antalya-Diplomatieforums führt Außenminister Ruslan Kasakbajew Gespräche u. a. mit sei- } \\
\text { nem pakistanischen Amtskollegen Shah Mahmood Qureshi. Laut Qureshi stellt Pakistan Kirgistan weiterhin } \\
\text { die Möglichkeit in Aussicht, die Häfen Karatschi und Gwadar zu nutzen }\end{array}$ \\
\hline 28.6 .2021 & $\begin{array}{l}\text { Präsident Dschaparow wird in Aschgabat von seinem turkmenischen Amtskollegen Gurbanguly Berdymu- } \\
\text { chammedow zu Gesprächen empfangen. Beide Seiten einigen sich u. a. auf die Schaffung eines } 100 \text { Mio. US- } \\
\text { Dollar schweren kirgisisch-turkmenischen Entwicklungsfonds. }\end{array}$ \\
\hline 29.6 .2021 & $\begin{array}{l}\text { Präsident Dschaparow wird in Duschanbe von seinem tadschikischen Amtskollegen Emomali Rachmon zu } \\
\text { Gesprächen empfangen. In einer gemeinsamen Abschlusserklärung bekräftigen beide Seiten u. a. ihr Ziel, künf- } \\
\text { tige Grenzkonflikte zu vermeiden. Die aktuelle Situation in Afghanistan wird von beiden Seiten mit Besorg- } \\
\text { nis wahrgenommen. }\end{array}$ \\
\hline 30.6 .2021 & $\begin{array}{l}\text { Präsident Dschaparow erlässt ein Dekret, wonach das Personal der Präsidialadministration, von Ministerien, } \\
\text { staatlichen Komitees, Behörden und Lokalverwaltungen um } 30 \text { \% reduziert werden soll. Insgesamt werden } \\
11.000 \text { Stellen gestrichen. }\end{array}$ \\
\hline 5.7.2021 & $\begin{array}{l}\text { Außenminister Kasakbajew wird in Baku von seinem aserbaidschanischen Amtskollegen Ali Asadow zu Gesprä- } \\
\text { chen empfangen. Beide Seiten einigen sich auf die Schaffung eines gemeinsamen Investmentfonds und eine } \\
\text { weitere Zusammenarbeit im Kontext der Pandemie. }\end{array}$ \\
\hline
\end{tabular}




\begin{tabular}{|l|l|}
\hline 5.7.2021 & $\begin{array}{l}\text { Der türkische Präsident Erdoğan gibt in einer TV-Rede bekannt, dass der türkische Nachrichtendienst MIT } \\
\text { „eine weitere erfolgreiche Spezialoperation im Ausland durchgeführt hat", in deren Ergebnis Orhan Inandi in } \\
\text { die Türkei gebracht und wegen Verbindungen zur dort verbotenen Gülen-Bewegung vor Gericht gestellt wurde. }\end{array}$ \\
\hline 6.7.2021 & $\begin{array}{l}\text { Das Außenministerium überreicht dem türkischen Botschafter eine Note, in dem die Entführung von Orhan } \\
\text { Inandi durch den türkischen Nachrichtendienst als unzulässig bezeichnet wird. Die Türkei wird aufgefordert, } \\
\text { Inandi nach Kirgistan zurückzubringen. }\end{array}$ \\
\hline 6.7.2021 & $\begin{array}{l}\text { Laut dem US-amerikanischen Beratungsunternehmen »Mercer« ist Bischkek unter 209 berücksichtigten Städ- } \\
\text { ten für Expats aktuell die günstigste Stadt der Welt. }\end{array}$ \\
\hline $\begin{array}{l}\text { Sadyr Dschaparow unterzeichnet ein Gesetz, das NGOs und gemeinnützige Organisationen dazu verpflichtet, } \\
\text { dem Finanzamt regelmäßig Finanzierungsquellen und Ausgabenposten offenzulegen. Kritiker:innen sehen hie- } \\
\text { rin einen Versuch, die Arbeit unabhängiger NGOs im Land zu behindern. }\end{array}$ \\
$\begin{array}{l}\text { An der kirgisisch-tadschikischen Grenze nahe des Gebirgspasses Tschaschmagildan (Gebiet Batken) kommt es } \\
\text { erneut zu einem Schusswechsel zwischen Grenzsoldaten beider Staaten. Offenbar eröffneten tadschikische Solda- } \\
\text { ten das Feuer, nachdem vier kirgisische Soldaten unbefugt tadschikisches Territorium betraten. Laut unbestätig- } \\
\text { ten Meldungen wurde ein kirgisischer Soldat getötet und ein Soldat von tadschikischen Beamten festgenommen. }\end{array}$ \\
\hline 8.7.2021
\end{tabular}




\section{Tadschikistan}




\begin{tabular}{|c|c|}
\hline 24.5 .2021 & Kirgistan schließt seine gemeinsame Grenze zu Tadschikistan, meldet Asia-Plus. \\
\hline 25.5 .2021 & 177 tadschikischen Flugreisenden wird in Bischkek die Einreise nach Kirgistan verwehrt. \\
\hline 28.5 .2021 & $\begin{array}{l}\text { Ein Moskauer Militärgericht verurteilt fünf tadschikische Staatsangehörige zu Haftstrafen zwischen } 9 \text { und } \\
17 \text { Jahren. Den Urteilen zufolge hätten die Beschuldigten islamistisch motivierte Terroranschläge im Raum } \\
\text { Moskau geplant. }\end{array}$ \\
\hline 2.6 .2021 & $\begin{array}{l}\text { Ein Gericht im Gebiet Sughd verurteilt Mirzo Chodschimuhammad, ehemaliger Vorsitzender der seit } 2015 \\
\text { verbotenen Islamischen Wiedergeburtspartei (IRPT), zu fünf Jahren Haft. }\end{array}$ \\
\hline 2.6 .2021 & $\begin{array}{l}\text { Innenminister Ramazon Rahimzoda und sein iranischer Amtskollege Rahmoni Fazli unterzeichnen eine } \\
\text { Absichtserklärung, die eine engere bilaterale Zusammenarbeit im Kampf gegen Kriminalität und Terroris- } \\
\text { mus vorsieht. }\end{array}$ \\
\hline 10.6 .2021 & $\begin{array}{l}\text { In Duschanbe empfängt Präsident Emomali Rachmon seinen usbekischen Amtskollegen Schawkat Misrijojew. } \\
\text { Bei dem Treffen werden Handelsgeschäfte im Wert von } 1 \text { Mrd. US-Dollar beschlossen. }\end{array}$ \\
\hline 12.6 .2021 & $\begin{array}{l}\text { Vor dem Bezirksgericht Gafurow in Chudschand beginnt ein Prozess gegen } 18 \text { mutmaßliche Mitglieder der } \\
\text { "Salafia«-Bewegung. Der tadschikische Dienst von RFE/RL berichtet in diesem Zusammenhang von Folter- } \\
\text { vorwürfen gegen die Ermittlungsbehörden. }\end{array}$ \\
\hline 17.6 .2021 & $\begin{array}{l}\text { Für die Sanierung des Pamir Highways zwischen Qala-i-Chumb und Wandsch (Autonomes Gebiet Berg-Bad- } \\
\text { achschan) stellt China Tadschikistan } 204 \text { Mio. US-Dollar zur Verfügung. }\end{array}$ \\
\hline 21.6 .2021 & $\begin{array}{l}\text { Erstmals seit Januar meldet Tadschikistan Corona-Neuinfektionen. Zuvor waren Meldungen über Coronaaus- } \\
\text { brüche im Land dementiert worden, meldet u. a. Eurasianet. }\end{array}$ \\
\hline 22.6 .2021 & $\begin{array}{l}\text { Der tadschikisch-afghanische Grenzübergang Scherchan-Bandar wird auf afghanischer Seite von Talibankämp- } \\
\text { fern erobert. } 130 \text { afghanische Soldaten fliehen auf tadschikisches Territorium. }\end{array}$ \\
\hline 23.6 .2021 & $\begin{array}{l}\text { Präsident Rachmon empfängt Vertreter:innen der acht Mitgliedsstaaten der Schanghaier Organisation für } \\
\text { Zusammenarbeit (SCO) in Duschanbe. Zu den Themenschwerpunkten zählt die aktuelle Sicherheitslage in } \\
\text { Afghanistan. }\end{array}$ \\
\hline 24.6 .202 & $\begin{array}{l}\text { Präsident Rachmon und sein usbekischer Amtskollege Schawkat Mirsijojew besprechen telefonisch die »besorg- } \\
\text { niserregende Lage im benachbarten Afghanistan«. }\end{array}$ \\
\hline 29.6 .2021 & $\begin{array}{l}\text { Präsident Rachmon empfängt seinen kirgisischen Amtskollegen Sadyr Dschaparow in Duschanbe. In einer } \\
\text { gemeinsamen Abschlusserklärung bekräftigen sie u. a. ihr Ziel, künftige Grenzkonflikte zu vermeiden. Beide } \\
\text { Seiten äußern sich besorgt zur aktuellen Situation in Afghanistan. }\end{array}$ \\
\hline 5.7 .2 & $\begin{array}{l}\text { 1.037 afghanische Soldaten fliehen nach Gefechten mit den Taliban über die afghanisch-tadschikische Grenze } \\
\text { nach Tadschikistan. Der tadschikische Grenzschutzdienst meldet Übertritte u. a. aus Chorog, Ischkaschim } \\
\text { und Langar (Autonomes Gebiet Berg-Badachschan). }\end{array}$ \\
\hline 5.7 .2 & $\begin{array}{l}\text { Ein Taliban-Sprecher gibt gegenüber RIA-Novosti bekannt, dass } 70 \% \text { der afghanisch-tadschikischen Grenze } \\
\text { von den Taliban kontrolliert würden. Zudem bezeichnet er Tadschikistan als »freundliches Land« und sichert } \\
\text { den Respekt vor der territorialen Integrität Tadschikistans zu. }\end{array}$ \\
\hline 5.7.2021 & $\begin{array}{l}\text { Im Rahmen einer Dringlichkeitssitzung des Sicherheitsrates weist Präsident Rachmon die Mobilisierung von } \\
20.000 \text { Reservesoldat:innen an, um die afghanische Grenze zu sichern. }\end{array}$ \\
\hline 6.7 .2021 & $\begin{array}{l}\text { 2.300 nach Tadschikistan geflohene afghanische Soldaten werden nach Afghanistan zurückgeführt. Dies gibt } \\
\text { Hamdulla Mohib, Nationaler Sicherheitsberater Afghanistans, bekannt. }\end{array}$ \\
\hline 6.7 .2021 & $\begin{array}{l}\text { Russlands stellv. Außenminister Andrei Rudenko gibt bekannt, dass der 201. Russische Militärstützpunkt in } \\
\text { Tadschikistan »mit allem ausgestattet sei«, um Tadschikistan »im Bedarfsfall zu unterstützen.» }\end{array}$ \\
\hline 7.7.2021 & $\begin{array}{l}\text { Bei einer Sitzung der Organisation des Vertrages über kollektive Sicherheit (CSTO) bittet Tadschikistan die } \\
\text { Mitgliedsstaaten um Unterstützung bei der Sicherung der afghanischen Grenze. }\end{array}$ \\
\hline 7.7.2021 & $\begin{array}{l}\text { In Sozialen Netzwerken kursiert ein Video, in dem Talibankämpfer am Grenzübergang Scherchan-Bandar } \\
\text { beim Abwickeln des Warenverkehrs mit Tadschikistan zu sehen sind. }\end{array}$ \\
\hline 8.7 .2021 & $\begin{array}{l}\text { In Moskau empfängt der Sonderbeauftragter des russischen Präsidenten für Afghanistan, Zamir Kabulow, Ver- } \\
\text { treter des politischen Büros der Taliban. Die Talibanvertreter versichern, die Grenzen der zentralasiatischen } \\
\text { Republiken nicht zu verletzen, meldet u. a. Asia-Plus. }\end{array}$ \\
\hline 8.7.2021 & $\begin{array}{l}\text { Die Verwaltung des Autonomen Gebietes Berg-Badachschan veröffentlicht ein Facebook-Video, welches über } \\
\text { die Aufnahme ziviler Flüchtlinge aus Afghanistan in Chorog berichtet. Fergana Agency zufolge wurden bis- } \\
\text { lang insgesamt } 1.400 \text { zivile Flüchtlinge aus Afghanistan aufgenommen. }\end{array}$ \\
\hline
\end{tabular}


Turkmenistan 


\begin{tabular}{|c|c|}
\hline 26.5.2021 & $\begin{array}{l}\text { Präsident Gurbanguly Berdymuchammedow empfängt den usbekischen Außenminister Abdulasis Kamilow } \\
\text { in Aschgabat zu Gesprächen über die grenzüberschreitende Wassernutzung. }\end{array}$ \\
\hline 1.6 .2021 & $\begin{array}{l}\text { Turkmen Railways gibt bekannt, dass der Personenzugverkehr im Land gesamten Land wiederaufgenommen } \\
\text { wurde. Der Personenzugverkehr war seit Juli } 2020 \text { unterbrochen. }\end{array}$ \\
\hline 3.6.2021 & $\begin{array}{l}\text { Das iranische Energieministerium kündigt an, wegen einer erhöhten Energienachfrage in der iranischen Pro- } \\
\text { vinz Chorasan ab sofort Strom aus Turkmenistan zu beziehen. }\end{array}$ \\
\hline 10.6 .2021 & $\begin{array}{l}\text { Der Präsidentensohn und stellvertretende Ministerkabinettsvorsitzende Serdar Berdymuchammedow wird in } \\
\text { Abu Dhabi u. a. vom emiratischen Außenminister Abdullah bin Zayed Al Nahyan zu Gesprächen empfangen. } \\
\text { Laut Arabian Business stellt der Abu Dhabi Funds for Development Turkmenistan } 100 \text { Mio. US-Dollar für } \\
\text { den Bau eines neuen Flughafens in Dschebel (Gebiet Balkan) bereit. }\end{array}$ \\
\hline 11.6 .2021 & $\begin{array}{l}\text { Laut dem stellvertretenden Ministerkabinettsvorsitzenden Schahym Abdrahmanow hat Turkmenistan alle } \\
\text { Schulden im Zusammenhang mit dem Bau der } 2009 \text { fertiggestellten Zentralasien-China-Gaspipeline gegen- } \\
\text { über China beglichen. Die Schuldsumme ist unbekannt. }\end{array}$ \\
\hline 14.6 .2021 & $\begin{array}{l}\text { Die Weltbank berücksichtigt Turkmenistan in diesem Jahr nicht in ihrem aktuellen Weltwirtschaftsbericht. } \\
\text { Als Grund wird das Fehlen von verlässlichen Daten angegeben. }\end{array}$ \\
\hline 17.6 .2021 & $\begin{array}{l}\text { Serdar Berdymuchammedow und Außenminister Raschid Meredow empfangen den EU-Sonderbeauftragten } \\
\text { für Zentralasien, Peter Burian, in Aschgabat. Beide Seiten bekunden ihr Interesse daran, turkmenischen Ener- } \\
\text { gieressourcen den Zugang zu europäischen Märkten zu ermöglichen. }\end{array}$ \\
\hline 17.6 .2021 & $\begin{array}{l}\text { Laut Chronika Turkmenistana werden private Bäckereien in Tedschen (Gebiet Ahal) dazu gezwungen, einen } \\
\text { Teil ihrer Backwaren zu staatlich festgelegten Preisen über staatliche Geschäfte zu verkaufen. Hintergrund sei } \\
\text { der gegenwärtige Mehlmangel in den staatlichen Bäckereien. }\end{array}$ \\
\hline 18.6 .2021 & $\begin{array}{l}\text { Laut dem turkmenischen Dienst von RFE/RL können Gaskunden mit ausstehenden Schulden im Gebiet Lebap } \\
\text { ab sofort nicht mehr in staatlichen Lebensmittelgeschäften einkaufen. }\end{array}$ \\
\hline 20.6.2021 & $\begin{array}{l}\text { Laut Interfax hat China im April 2,576 Mrd. } \mathrm{m}^{3} \text { Erdgas aus Turkmenistan bezogen. Der Preis beläuft sich } \\
\text { demnach auf } 216 \text { US-Dollar pro } 1.000 \mathrm{~m}^{3} .\end{array}$ \\
\hline 23.6 .2021 & $\begin{array}{l}\text { Laut Chronika Turkmenistana wird die Wasserversorgung von Haushalten in Aschgabat bereits seit einem } \\
\text { Monat jede Nacht unterbrochen, in einigen Bezirken auch tagsüber. Turkmenistan ist aktuell von einer schwe- } \\
\text { ren Dürre betroffen. }\end{array}$ \\
\hline 23.6 .2021 & Präsident Berdymuchammedow eröffnet in Kerki (Gebiet Lebap) einen internationalen Flughafen. \\
\hline 24.6 .2021 & $\begin{array}{l}\text { Präsident Berdymuchammedow empfängt den Präsidenten des staatlichen aserbaidschanischen Energiekon- } \\
\text { zerns SOCAR, Rovnag Abdullajew, in Aschgabat zu Gesprächen. Beide Seiten bekräftigen ihr Interesse an } \\
\text { einem Ausbau der Zusammenarbeit, u. a. bei der Exploration und Ausbeutung des Dostluk-Kohlenwasser- } \\
\text { stofffeldes im Kaspischen Meer. }\end{array}$ \\
\hline 25.6 .2021 & Laut dem turkmenischen Dienst von RFE/RL gibt es landesweit wieder vermehrte Fälle von Lungenentzündungen. \\
\hline 27.6 .2021 & $\begin{array}{l}\text { Bei einem Treffen der Kommission zur Bekämpfung der Ausbreitung von Infektionskrankheiten ordnet Präsi- } \\
\text { dent Berdymuchammedow den Import von weiteren 1,5 Mio. Dosen Impfstoff gegen Covid-19 an. Landesweit } \\
\text { soll die Polizei Hygienemaßnahmen wie soziale Distanzierung und das Tragen von Atemschutzmasken wieder } \\
\text { strenger kontrollieren. Offiziell wurde bisher kein Fall von Covid-19 in Turkmenistan gemeldet. }\end{array}$ \\
\hline 28.6 .2021 & $\begin{array}{l}\text { Präsident Berdymuchammedow empfängt seinen kirgisischen Amtskollegen Sadyr Dschaparow in Aschgabat zu } \\
\text { Gesprächen, u. a. über die Situation in Afghanistan und die andauernde Covid-19-Pandemie. Beide Seiten eini- } \\
\text { gen sich u. a. auf die Schaffung eines } 100 \text { Mio. US-Dollar schweren kirgisisch-turkmenischen Entwicklungs- } \\
\text { fonds und die Belieferung Kirgistans mit turkmenischem Erdgas und Strom in den Herbst- und Wintermonaten. }\end{array}$ \\
\hline 6.7.2021 & $\begin{array}{l}\text { Laut dem US-amerikanischen Beratungsunternehmen »Mercer«ist Aschgabat unter } 209 \text { berücksichtigten Städ- } \\
\text { ten für Expats aktuell die teuerste Stadt der Welt. }\end{array}$ \\
\hline 7.7.2021 & $\begin{array}{l}\text { Alle Personen über } 18 \text { Jahren sind laut der staatlichen Nachrichtenagentur TDH ab sofort dazu verpflichtet, } \\
\text { sich gegen Covid-19 impfen zu lassen. }\end{array}$ \\
\hline 8.7 .2021 & $\begin{array}{l}\text { Ein Bericht des britischen Außenministeriums stellt für } 2020 \text { keine merkliche Verbesserung der Menschen- } \\
\text { rechtslage in Turkmenistan fest. Demnach sei Folter in turkmenischen Gefängnissen weit verbreitet und die } \\
\text { Meinungsfreiheit würde weiterhin stark eingeschränkt. }\end{array}$ \\
\hline
\end{tabular}




\section{Usbekistan}




\begin{tabular}{|c|c|}
\hline 8.6.2021 & Aus den Gebieten Samarkand und Nawoi werden Unterbrechungen der Trinkwasserversorgung gemeldet. \\
\hline 9.6 .2021 & $\begin{array}{l}\text { In Angren (Gebiet Taschkent) werden Dutzende Männer von Mitarbeiter:innen des Innenministeriums vorge- } \\
\text { laden, um ihnen die Bärte abzurasieren, berichtet der usbekische Dienst von RFE/RL. }\end{array}$ \\
\hline 10.6 .2021 & $\begin{array}{l}\text { Präsident Mirsijojew trifft in Duschanbe seinen tadschikischen Amtskollegen Rachmon. Bei dem Treffen wer- } \\
\text { den Handelsgeschäfte im Wert von } 1 \text { Mrd. US-Dollar beschlossen. }\end{array}$ \\
\hline 16.6 .2021 & $\begin{array}{l}\text { In Taschkent werden Personen polizeilich verhört, die einen Monat zuvor an der Parteiversammlung der Par- } \\
\text { tei Erk (Wille) teilgenommen haben sollen, meldet RFE/RL. }\end{array}$ \\
\hline 18.6 .2021 & $\begin{array}{l}\text { Aus mehreren Landesteilen wird die Festnahme mutmaßlicher Terroristen gemeldet. Am 10. sowie 17. Juni } \\
\text { wurden u. a. im Gebiet Samarkand } 20 \text { Personen inhaftiert, darunter auch Anhänger der in Russland und Usbe- } \\
\text { kistan verbotenen Terrororganisation "Hizb ut-Tahrir«. }\end{array}$ \\
\hline 21.6 .2021 & $\begin{array}{l}\text { RFE/RL meldet, dass Studierende aus den Gebieten Surchandarjo, Chorezm sowie Buchara von Strafverfol- } \\
\text { gungsbeamten in Hochschulen aufgefordert würden, sich nicht den neugegründeten Parteien Chakikat wa } \\
\text { Taraqijot (Gerechtigkeit und Entwicklung) sowie Erk (Wille) anzuschließen. }\end{array}$ \\
\hline 21.6 .2021 & $\begin{array}{l}\text { In der Region Kegeilinsky (Republik Karakalpakstan) blockieren etwa } 20 \text { Personen eine Hauptstraße, nach- } \\
\text { dem zuvor die Auszahlung von Sozialleistungen verschoben wurde. }\end{array}$ \\
\hline 21.6 .2021 & $\begin{array}{l}\text { Das Justizministerium verweigert der neugegründeten Partei »Hakikat wa Taraqiot« die Registrierung, meldet } \\
\text { Eurasianet. Statt der gesetzlich vorgeschriebenen } 20.000 \text { Unterschriften habe die Partei lediglich } 9.873 \text { Unter- } \\
\text { schriften gesammelt, so das Ministerium. }\end{array}$ \\
\hline 22.6 .2021 & $\begin{array}{l}\text { Wegen der Veröffentlichung religiöser Inhalte wird Mahsudschon Askarow, Mitbegründer der Nachrichten- } \\
\text { plattform kun.uz, zu einer Geldstrafe von 12,25 Mio. Sum (1,100 USD) verurteilt. }\end{array}$ \\
\hline 22.6.2021 & $\begin{array}{l}\text { Premierminister Abdulla Aripow wird in Moskau von seinem russischen Amtskollegen Michail Mischustin emp- } \\
\text { fangen. Mischustin legt Aripow eine vollwertige Mitgliedschaft Usbekistans in der Eurasischen Wirtschafts- } \\
\text { union (EAEU) nahe. Neben wirtschaftlichen Wachstumsmöglichkeiten würde diese auch "greifbare Vorteile» } \\
\text { für die Bürger:innen Usbekistans bieten, so Mischustin. }\end{array}$ \\
\hline 24.6 .2021 & $\begin{array}{l}\text { Aus dem Gebiet Surchandarjo wird der Grenzübertritt von } 53 \text { afghanischen Soldaten sowie Kämpfer einer } \\
\text { lokalen Miliz gemeldet. Der Pressedienst des usbekischen Außenministeriums meldet die Rückführung sämt- } \\
\text { licher Personen. }\end{array}$ \\
\hline 25.6 .2021 & $\begin{array}{l}\text { Das Verteidigungsministerium startet landesweit Militärübungen, um »Truppen in Kampfbereitschaft zu brin- } \\
\text { gen«, meldet RFE/RL. }\end{array}$ \\
\hline 26.6 .2021 & $\begin{array}{l}\text { Aus dem Gebiet Surchandarjo wird erneut der Grenzübertritt mehrerer Dutzend afghanischer Soldaten sowie } \\
\text { Kämpfer lokaler Milizen gemeldet. Sämtliche Personen wurden wieder nach Afghanistan zurückgeführt, mel- } \\
\text { den verschiedene Quellen, u. a. Eurasianet. }\end{array}$ \\
\hline 28.6 .2021 & In Taschkent werden ab sofort Impfungen in Supermärkten und auf Märkten angeboten, meldet RFE/RL. \\
\hline 30.6 .2021 & $\begin{array}{l}\text { Der usbekische Dienst von RFE/RL berichtet, dass Unternehmen und Organisationen landesweit durch die } \\
\text { Gesundheitsbehörden angehalten werden, ihre Mitarbeiter:innen zu impfen. }\end{array}$ \\
\hline 30.6 .2021 & $\begin{array}{l}\text { Im Zusammenhang mit der Talibanoffensive in Nordafghanistan werden die Kontrollen entlang der usbekisch- } \\
\text { afghanischen Grenze verstärkt, Behörden und Imame rufen zu Wachsamkeit auf. }\end{array}$ \\
\hline 30.6 .2021 & $\begin{array}{l}\text { Angaben des Gesundheitsministeriums zufolge teilen sich Usbekistans Impfstoffbestände wie folgt auf: 6,5 Mio. } \\
\text { Dosen des chinesischen Impfstoffs "ZF-UZ-VAC2001« sowie insgesamt 7,4 Mio. Dosen AstraZeneca und Sput- } \\
\text { nik-V. } 4 \text { \% der Bevölkerung sind vollständig geimpft, meldet RFE/RL. }\end{array}$ \\
\hline 2.7 .2021 & $\begin{array}{l}\text { Die Nutzung Sozialer Medien ist landesweit eingeschränkt. Hintergrund ist eine Gesetzesänderung, wonach } \\
\text { Internetdienstleister seit dem 15.4.2021 sämtliche personenbezogenen Daten von Nutzer:innen auf Servern im } \\
\text { Inland speichern müssen. }\end{array}$ \\
\hline 3.7 .2021 & $\begin{array}{l}\text { Eurasianet meldet, dass Usbekistan sich offenbar auf einen potenziellen Flüchtlingsstrom aus Afghanistan vor- } \\
\text { bereitet. Offenbar wurde zu diesem Zweck in Termez eine Zeltstadt errichtet. }\end{array}$ \\
\hline 5.7.2021 & Fergana Agency berichtet, dass die Nutzung von Virtual Private Networks (VPN) im Land stark angestiegen sei. \\
\hline 5.7.2021 & $\begin{array}{l}\text { Präsident Mirsijojew unterzeichnet ein neues Religionsgesetz, das die Registrierung religiöser Organisationen } \\
\text { vereinfachen soll. Das Tragen religiöser Kleidung, welche zuvor nur von Geistlichen getragen werden durfte, } \\
\text { ist nun allen Bürger:innen erlaubt. }\end{array}$ \\
\hline 6.7.2021 & $\begin{array}{l}\text { Anwält:innen der inhaftierten Tochter des verstorbenen Ex-Präsidenten Islam Karimow, Gulnara Karimowa, for- } \\
\text { dern die Vereinten Nationen auf, ihre Mandantin als "willkürlich inhaftiert« anzuerkennen, berichtet RFE/RL. }\end{array}$ \\
\hline
\end{tabular}


Herausgeber:

Zentrum für Osteuropa- und internationale Studien (Z0iS) gGmbH

Deutsche Gesellschaft für Osteuropakunde e.V.

Deutsches Polen-Institut

Forschungsstelle Osteuropa an der Universität Bremen

Leibniz-Institut für Agrarentwicklung in Transformationsökonomien

Leibniz-Institut für Ost- und Südosteuropaforschung

Redaktion:

Verantwortliche Redakteure: Rostam Onsori und Richard Schmidt

Satz: Matthias Neumann

\section{Wissenschaftlicher Beirat:}

Dr. Luca Anceschi, University of Glasgow

Dr. Beate Eschment, Zentrum für Osteuropa- und internationale Studien (Z0iS), Berlin

Prof. Dr. Martin Petrick, Leibniz-Institut für Agrarentwicklung in Transformationsökonomien, Halle

Die Meinungen, die in den Zentralasien-Analysen geäußert werden, geben ausschließlich die Auffassung der Autoren wieder. Abdruck und sonstige publizistische Nutzung sind nach Rücksprache mit der Redaktion gestattet.

Zentralasien-Analysen-Layout: Matthias Neumann, nach einem Konzept von Cengiz Kibaroglu, mit einer Grafik von Sebastian Klüsener Alle Ausgaben der Zentralasien-Analysen sind mit Themen- und Autorenindex archiviert unter www.laender-analysen.de

ISSN 1866-2110 @ 2021 by Zentrum für Osteuropa- und internationale Studien (ZOiS) gGmbH, Deutsche Gesellschaft für Osteuropakunde e.V., Deutsches Polen-Institut, Forschungsstelle Osteuropa an der Universität Bremen, Leibniz-Institut für Agrarentwicklung in Transformationsökonomien, Leibniz-Institut für Ost- und Südosteuropaforschung

Zentrum für Osteuropa- und internationale Studien (Z0iS) g gmbH • Mohrenstraße 60 • 10117 Berlin • Telefon: +49 (30) 2005949-20

e-mail:rostam.onsori@zois-berlin.de, richard.schmidt@zois-berlin.de•Internet-Adresse: www.laender-analysen.de/zentralasien 
ÄNDER-ANALYSEN

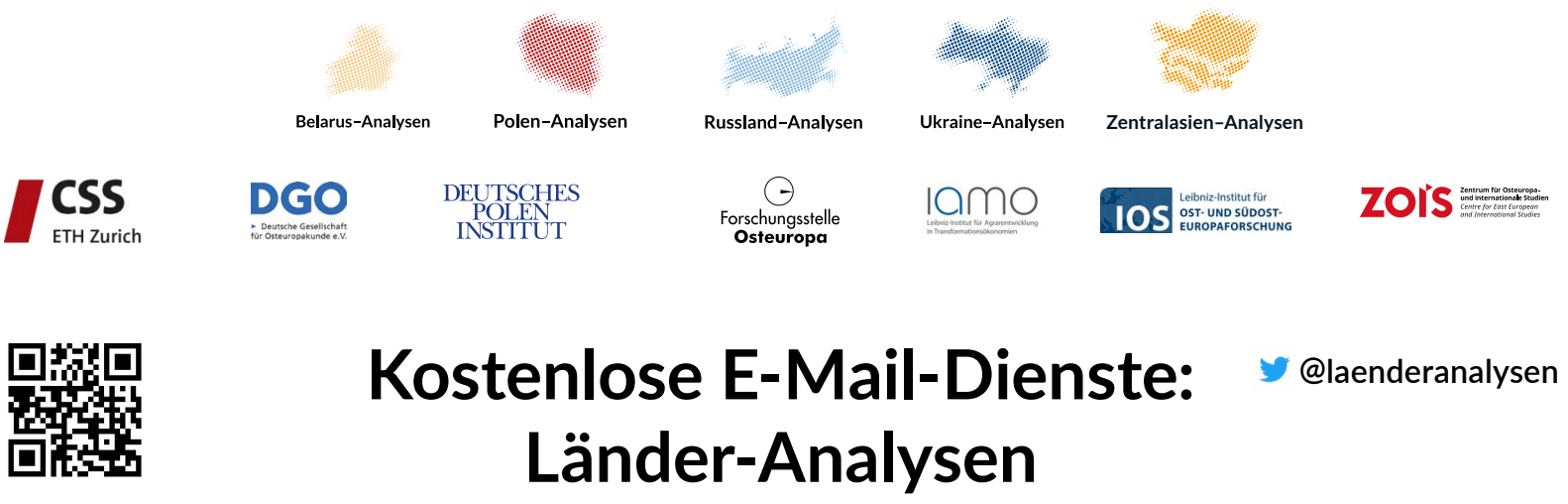

Die Länder-Analysen bieten regelmäßig im kostenlosen Abonnement kompetente Einschätzungen aktueller politischer, wirtschaftlicher, sozialer und kultureller Entwicklungen in Ostmitteleuropa und der GUS. Alle Länder-Analysen verstehen sich als Teil eines gemeinsamen Projektes, das der wissenschaftlich fundierten, allgemeinverständlich formulierten Analyse der Entwicklungen im östlichen Europa, der Offenheit für verschiedene inhaltliche Positionen und der kostenlosen und nicht-kommerziellen Information einer breit verstandenen interessierten Öffentlichkeit verpflichtet ist. Autor/innen sind internationale Fachwissenschaftler/innen und Expert/innen. Die Redaktionen der Länder-Analysen bestehen aus Wissenschaftler/innen mit langjähriger Forschungserfahrung.

Die deutschsprachigen Länder-Analysen werden gemeinsam von der Forschungsstelle Osteuropa an der Universität Bremen, dem Zentrum für Osteuropa- und internationale Studien, der Deutschen Gesellschaft für Osteuropakunde, dem Deutschen Polen-Institut, dem Leibniz-Institut für Agrarentwicklung in Transformationsökonomien und dem Leibniz-Institut für Ost- und Südosteuropaforschung herausgegeben. Die englischsprachigen Länder-Analysen erscheinen in Kooperation der Forschungsstelle Osteuropa mit dem Center for Security Studies (CSS) der ETH Zürich.

Die Länder-Analysen bieten regelmäßig Kurzanalysen zu aktuellen Themen, ergänzt um Grafiken und Tabellen sowie Dokumentationen. Zusätzlich gibt es eine Chronik aktueller Ereignisse.

\section{Belarus-Analysen}

Erscheinungsweise: zweimonatlich

Abonnement unter: http://www.laender-analysen.de/belarus/

\section{Caucasus Analytical Digest}

In englischer Sprache. Erscheinungsweise: zweimonatlich

Abonnement unter: http://www.css.ethz.ch/en/publications/cad.html

\section{Polen-Analysen}

Erscheinungsweise: zweimal monatlich

Abonnement unter: http://www.deutsches-polen-institut.de/newsletter/polen-analysen/

\section{Russland-Analysen}

Erscheinungsweise: zweimal monatlich

Abonnement unter: http://www.laender-analysen.de/russland/

\section{Russian Analytical Digest}

In englischer Sprache. Erscheinungsweise: zweimal monatlich Abonnement unter: http://www.css.ethz.ch/en/publications/rad.html

\section{Ukraine-Analysen}

Erscheinungsweise: zweimal monatlich

Abonnement unter: http://www.laender-analysen.de/ukraine/

\section{Zentralasien-Analysen}

Erscheinungsweise: zweimonatlich

Abonnement unter: http://www.laender-analysen.de/zentralasien/ 